\title{
RASA1-driven cellular export of collagen IV is required for the development of lymphovenous and venous valves in mice
}

Di Chen $\mathrm{PhD}^{1}$, Xin Geng $\mathrm{PhD}^{2}$, Philip E. Lapinski $\mathrm{PhD}^{1}$, Michael J. Davis $\mathrm{PhD}^{3}, \mathrm{R}$. Sathish Srinivasan $\mathrm{PhD}^{2}$, and Philip D. King $\mathrm{PhD}^{1}$

${ }^{1}$ Department of Microbiology and Immunology, University of Michigan Medical School, Ann Arbor, MI, USA; ${ }^{2}$ Cardiovascular Biology Research Program, Oklahoma Medical Research Foundation, Oklahoma City, OK, USA; ${ }^{3}$ Department of Medical Pharmacology and Physiology, University of Missouri, Columbia, MO, USA.

DC, XG, contributed equally to this manuscript. SS and PDK are co-corresponding authors.

Correspondence:

Philip D. King

Department of Microbiology and Immunology University of Michigan Medical School

6606 Med Sci II

1150 West Medical Center Drive

Ann Arbor

MI 48109-5620

Tel: 734-615-9073

Fax: 734-764-3562

E-mail: kingp@umich.edu 
RASA1, a negative regulator of the Ras-mitogen-activated protein kinase (MAPK) signaling pathway, is essential for the development and maintenance of lymphatic vessel (LV) valves. However, whether RASA1 is required for the development and maintenance of lymphovenous valves (LVV) and venous valves (VV) is unknown. In this study we show that induced endothelial cell (EC)-specific disruption of Rasal in mid-gestation mouse embryos did not affect initial specification of LVV or central VV but did affect their continued development. Similarly, switch to expression of a catalytically inactive form of RASA1 resulted in impaired LVV and VV development. Blocked development of LVV in RASA1-deficient embryos was associated with accumulation of the basement membrane protein, collagen IV, in LVV-forming EC and could be partially or completely rescued by MAPK inhibitors and drugs that promote collagen IV folding. Disruption of Rasal in adult mice resulted in venous hypertension and impaired VV function that was associated with loss of EC from VV leaflets. In conclusion, RASA1 functions as a negative regulator of Ras signaling in EC that is necessary for EC export of collagen IV, thus permitting the development of LVV and the development and maintenance of VV. 


\section{Introduction}

The Ras signaling pathway is a ubiquitous intracellular signaling pathway that is triggered by different growth factor receptors (GFR) in numerous cell types. ${ }^{1,2}$ Ras is a small GTP-binding protein, tethered to the inner leaflet of the cell membrane, which switches between inactive GDP-bound and active GTP-bound states. GFR activate Ras through recruitment to membranes of one or more Ras guanine nucleotide exchange factors (RasGEFs) that eject GDP from the Ras guanine nucleotide-binding pocket, thus permitting Ras to bind GTP. ${ }^{3}$ Activated GTP-bound Ras induces different downstream signaling cascades including the mitogen-activated protein kinase (MAPK) and phosphatidylinositol 3-kinase (PI3K) signaling cascades that couple GFR and Ras to cellular responses. ${ }^{4,5}$ Inactivation of Ras is mediated by Ras GTPase-activating proteins (RasGAPs) that increase the ability of Ras to hydrolyze bound GTP to GDP by several orders of magnitude. ${ }^{6}$

There are ten different members of the RasGAP family that each comprise of a catalytically active GAP domain together with one or more modular binding domains. ${ }^{6}$ Most members of the RasGAP family are expressed broadly in different tissues and cell types. Nonetheless, one RasGAP family member, p120 RasGAP (also known as RASA1), has emerged as a critical regulator of blood vessel (BV) and lymphatic vessel (LV) systems in both humans and mice. In humans, germline inactivating mutations of the RASAl gene cause the autosomal dominant blood vascular disorder, capillary malformation-arteriovenous malformation (CM-AVM). ${ }^{7-9}$ Recent evidence indicates that the development of BV lesions in CM-AVM is dependent upon the acquisition of somatic 
inactivating second hit mutations in the intact $R A S A 1$ allele in endothelial cells (EC) or their progenitors during development. ${ }^{10,11}$ This is consistent with the variable phenotype and location of BV lesions in CM-AVM patients. In addition, LV abnormalities, including lymphedema, chylous ascites, chylothorax and LV hyperplasia have also been observed in some CM-AVM patients..$^{8,9,11-14}$

Non-conditional disruption of the Rasal gene in mice results in mid-gestation lethality (E10.5) as a consequence of abnormal vasculogenesis and developmental angiogenesis in which primitive vascular plexuses are remodeled into hierarchical arterial-capillaryvenous networks. ${ }^{15,16}$ In addition, disruption of Rasal in neonatal and adult mice results in impaired retinal angiogenesis and pathological angiogenesis respectively. ${ }^{17-19} \mathrm{We}$ recently demonstrated that in the absence of RASA1, endothelial cells (EC) are unable to export the extracellular matrix protein, collagen IV, which is major constituent of vascular basement membranes (BM). This inability to export collagen IV, accounts for the impaired developmental, neonatal and pathological angiogenic responses in the absence of RASA1.

Concerning the LV system, induced disruption of Rasal in adult mice results in LV leakage in the form of chylous ascites and chylothorax. ${ }^{18}$ This can be explained on the basis that RASA1 is required for the maintenance of intra-luminal valves in collecting LV that normally prevent backflow of lymph fluid. ${ }^{20}$ Upon Rasal disruption, lymphatic EC (LEC) are lost from LV valve leaflets at the rate of approximately one LEC per leaflet per week until a threshold point is reached where the valve is unable to prevent fluid 
backflow and is unable to function. ${ }^{20}$ RASA1 is also necessary for the development of LV valves in late gestation. Disruption of Rasal just prior to LV valvulogenesis at E15.5 does not impact upon initial LV valve specification characterized by increased expression of the PROX1 transcription factor in valve-forming LEC. ${ }^{20,21}$ However, all PROX1 ${ }^{\text {hi }}$ valve-forming LEC undergo apoptosis shortly thereafter and valve development ceases. ${ }^{20}$

Lymph fluid is returned to the blood circulation via LV that connect with the blood vasculature at the junction of the internal jugular vein (IJV), external jugular vein (EJV) and subclavian veins (SCV) with the superior vena cava (SVC). ${ }^{22,23}$ Lymphovenous valves (LVV) guard the four points of connection of these LV with the blood vasculature (two points of connection on either side of the animal) and, thereby, prevent backflow of blood into LV. ${ }^{22,23} \mathrm{LVV}$ first form at E12 at the point of contact of lymphatic sacs (LS) with the blood vasculature. LVV specification is marked by the up-regulation of PROX1 by both LEC on the lymphatic side and LVV-forming EC on the venous side of the nascent valve structure. ${ }^{22,23}$ LVV development then proceeds through the successive stages of delamination, aggregation and maturation as LVV leaflets form and extend into the vein lumen; a process that is considered complete by E16.5. ${ }^{22}$ Mature LVV leaflets comprise of two different types of EC attached to a central extracellular matrix (ECM) core. ${ }^{22} \mathrm{EC}$ on the lymphatic and venous sides of leaflets continue to express high levels of PROX1. LEC on the lymphatic side of leaflets express high levels of vascular endothelial growth factor receptor 3 (VEGFR3), the receptor for VEGF-C. In contrast, EC on the venous side of LVV leaflets express low levels of VEGFR3 while the rest of the venous endothelial cells are VEGFR3 negative. Since RASA1 is necessary for the 
development of LV valves, it is important to determine if it performs a similar function in the development of LVV and, if so, at which stage.

VV prevent backflow of blood and are required for unidirectional flow of blood in veins $^{24}$. Dysfunction of VV has serious consequences that include chronic venous insufficiency, venous hypertension and deep vein thrombosis. ${ }^{25,26}$ Development of VV in central veins, such as the IJV, EJV and SCV, is initiated at E14.5 and is completed by E16.5. ${ }^{22,27}$ In contrast, VV in peripheral veins, such as the saphenous vein, develop postnatally. ${ }^{27,28} \mathrm{VV}$ specification, like LV valve and LVV specification, is marked by increased expression of PROX1 in valve-forming EC. ${ }^{22,24}$ Mature VV are structurally similar to LV valves in that leaflets of both type of valve comprise of a single type of EC attached to a central ECM core. VV and LV valve leaflet EC both continue to express high levels of PROX1 and share several other molecular characteristics including high level expression of the FOXC2 transcription factor and alpha-9 integrin. ${ }^{22,24}$ Given the similarity between VV and LV valves, investigation as to whether or not RASA1 is necessary for the development and maintenance of VV is also important.

In the current studies, we used different mouse models of RASA1 deficiency to demonstrate a role for RASA1 in the development and maintenance of LVV and VV. Furthermore, we established that RASA1 is necessary for the export of collagen IV from valve-forming EC, which explains its role in valve development. Studies are of potential relevance to an understanding of the pathogenesis of CM-AVM and are of additional significance to other cardiovascular diseases. 


\section{Results}

RASA1 is not required for the specification of $L V V$ and central VV. Specification of LVV occurs at E12 and is marked by increased expression of PROX1 in LEC and LVVforming $\mathrm{EC}$ at the points that LS make contact with BV in the region of the junction of the IJV, EJV, SCV and SVC. ${ }^{22,23}$ Therefore, to examine if RASA1 plays a role in LVV specification, we administered TM to pregnant Rasa $1^{f l / f l}$ mice carrying Rasa $^{f l / f l}$ and Rasa ${ }^{f l f l}{ }^{\text {Cl }} d h 5^{\text {ert2cre }}$ embryos at E10.5 and analyzed embryos at E12.5. The Cdh5 promoter drives expression of the ert2cre transgene within EC specifically. ${ }^{29}$ As assessed by staining of frontal tissue sections for PROX1, VEGFR3 and CD31, induced disruption of Rasal at E10.5 in Rasal ${ }^{f l f l} C d h 5^{\text {ert2cre }}$ embryos did not affect LVV specification (Figure $1 \mathrm{~A})$.

We also examined if RASA1 was required for the specification of central VV. Specification of the VV that guard the points of entry of the IJV, EJV and SCV into the SVC occurs at E14.5. ${ }^{22,27}$ Similar to LVV and LV valve specification, VV specification is characterized by increased expression of PROX1 and VEGFR3 in VV-forming EC.

Therefore, to examine if RASA1 is required for VV specification, we administered TM to pregnant Rasal $1^{f l f l}$ mice carrying Rasal ${ }^{f l f l}$ and Rasal $1^{f l f l} C_{d h 5^{\text {ert2cre }}}$ embryos at E12.5 and analyzed embryos at E14.5 for PROX1 and VEGFR3 expression at the respective venous junctions (Figure 1 B). Loss of RASA1 in EC at E12.5 did not affect VV specification. Therefore, RASA1 is dispensable for the specification of VV as well as LVV. 


\section{RASA1 is required for the continued development of LVV and central VV.}

Development of LVV and central VV continues through E16.5 as valve leaflets are extended into the vessel lumen. ${ }^{22,23}$ To determine if RASA1 is required for continued LVV and central VV development, we administered TM to Rasal ${ }^{f l / f l}$ and Rasal $1^{f l f l}$ $C d h 5^{\text {ert2cre }}$ embryos at E12.5 and analyzed embryos at E16.5. LVV and VV structure was analyzed by immunostaining of tissue sections and by SEM (Figure 2 A and B). In Rasal $1^{f l f l}$ control embryos, one pair of normal LVV was identified at the vast majority of examined LV-BV junctions (Figure $2 \mathrm{C}$ ). In contrast, in Rasa $1^{f l f l} C d h 5^{\text {ert2cre }}$ embryos, most LV-BV junctions contained no LVV and a minority contained only one LVV. None of the examined LV-BV junctions contained two LVV (Figure 2 C). Similarly, in Rasal ${ }^{f l f l}$ control embryos, normal VV were found at all examined junctions of the IJV, EJV and SCV with the SVC (Figure $2 \mathrm{D}$ and E). In contrast, in Rasal ${ }^{f l f l}$ Cdh $^{\text {ert2cre }}$ embryos, development of central VV was severely impaired. In the majority of cases, all three VV were absent and in the remaining cases, only a rudimentary EJV VV could be identified whereas the IJV and SCV VV were also absent (Figure 2 D and E). Thus, although RASA1 is not required for initial specification of LVV and central VV, it is required for their continued development.

\section{Impaired development of LVV and central VV in embryos that express RASA1}

R780Q alone. Some studies have indicated that RASA1 can participate in intracellular signaling pathways independent of its ability to promote Ras hydrolysis of GTP. ${ }^{6}$

Therefore, we examined if the function of RASA1 in LVV and central VV development was dependent upon its catalytic GAP activity. For this purpose, we used a $\operatorname{Rasa} 1^{R 780 Q}$ 
allele that we reported previously. ${ }^{20}$ R780 of RASA1 is the "arginine finger" of the GAP domain that is essential for GAP activity. ${ }^{6,16}$ Mutation of this arginine to glutamine in R780Q thus abrogates GAP activity, although is predicted to leave all other putative RASA1 functions intact. Since Rasal $1^{R 780 Q / R 780 Q}$ embryos die at E10.5 of gestation ${ }^{16}$, we generated Rasal $1^{f l / R 780 Q}$ embryos with ubiquitin promoter-driven $\operatorname{ert} 2 \mathrm{cre}\left(U \mathrm{Ub}^{\text {ert2cre }}\right)$ to examine a requirement of RASA1 GAP activity for LVV and central VV development. TM was administered to Rasa $1^{f l / R 780 Q} U b^{\text {ert2cre }}$ embryos and control Rasal $1^{f l / f l}$ and Rasal $1^{f l / R 780 Q}$ embryos at E12.5 and LVV and VV development was analyzed at E16.5 as before (Figure 3 A). Compared to controls, Rasa ${ }^{f l / R 780 Q} U b^{\text {ert2cre }}$ embryos showed impaired development of LVV and VV. The majority of LV-BV junctions in Rasa $1^{f l / R 780 Q}$ $U b^{\text {ert2cre }}$ embryos contained only one LVV (Figure 3 B). Furthermore, the majority of examined vessels from Rasal $1^{f l / R 780 Q} \mathrm{Ub}^{\text {ert2cre }}$ embryos contained no VV at the junctions of the IJV and SCV with the SVC (Figure $3 \mathrm{C}$ ). Nonetheless, the impact of switch to expression of RASA1 R780Q alone upon LVV and VV development was less than that observed following complete loss of RASA1 in EC (Figure 2). This finding is consistent with the notion that RASA1 regulates LVV and VV development through both GAP domain dependent and GAP domain independent mechanisms.

\section{MAPK inhibition partially rescues LVV development in the absence of RASA1. EC} in developing LVV in Rasal $1^{f l f l} C_{d h 5^{\text {ert2cre }}}$ embryos administered TM at E12.5 showed increased activation of MAPK at E14.5 (Figure 4 A and B). Therefore, we next asked if inhibition of MAPK could rescue development of LVV and central VV in TM-treated

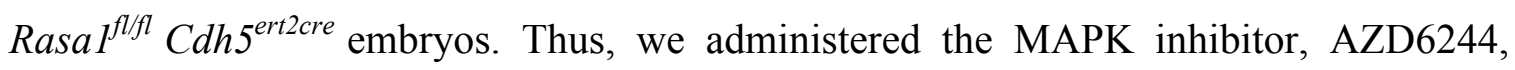


along with TM to Rasa ${ }^{f l f l} C d h 5^{\text {ert2cre }}$ and Rasa ${ }^{f l / f l}$ control embryos at E12.5 and on each subsequent day thereafter until embryo harvest at E16.5. AZD6244 had a significant rescue effect upon LVV development in TM-treated Rasa $1^{f l f l} C d h 5^{\text {ert2cre }}$ embryos (Figure $4 \mathrm{C}$ and D). Whereas in the absence of AZD6244 treatment, the majority of LV-BV junctions contained no LVV, in the presence of AZD6244 the majority of LV-BV junctions contained at least one LVV and in some cases two LVV were identified. AZD6244 had no influence upon LVV development in TM-treated Rasal ${ }^{f l f l}$ embryos. These findings indicate that impaired LVV development results in part from dysregulated activation of the MAPK pathway. Surprisingly, despite the finding of significant impairment of central VV development in embryos that express RASA1 R780Q alone, AZD6244 was largely unable to rescue central VV development in TM-treated Rasa flffl Cdh5 $5^{\text {ert2cre }}$ embryos (Figure $4 \mathrm{C}$ and E). Therefore, impaired development of central VV in the absence of RASA1 may be more dependent upon dysregulated activation of distinct effector pathways downstream of activated Ras.

\section{Loss of RASA1 results in accumulation of collagen IV in EC of LVV. We recently} determined that global or EC-specific disruption of Rasal at E13.5 results in the apoptotic death of all dermal EC at E18.5 or E19.5 respectively. ${ }^{19}$ In the absence of RASA1, the vascular BM protein, collagen IV, is retained within the endoplasmic reticulum (ER) of EC and smooth muscle cells. As a result of the reduced amounts of collagen IV in BM, EC fail to attach properly to BM and undergo apoptotic death. Based upon these findings, we asked if induced loss of RASA1 at E12.5 results in intracellular accumulation of collagen IV in EC of LVV. An inability of LVV EC to export collagen 
IV for deposition in the ECM core of developing LVV leaflets would provide an explanation for failed LVV development. In embryos administered TM at E12.5, developing LVV are present at E14.5 (Figure 1 B) but absent at E16.5 (Figure 2). Therefore, we examined E15.5 embryos for any evidence of EC collagen IV accumulation in LVV EC. At E15.5, LVV in TM-treated (at E12.5) Rasal ${ }^{\text {flflf }}$ Cdh $^{\text {ert2cre }}$ embryos were frequently abnormal and separation of the two EC layers was often observed (Supplemental Figure 1). We examined collagen IV accumulation in embryos that additionally carried a Proxl-eGFP transgene. ${ }^{30}$ In LVV EC of Rasa $1^{\text {flffl }}$ embryos, eGFP should be present throughout the cell cytoplasm and nucleus resulting in the appearance of a broadly distributed cellular green fluorescence signal. In contrast, in LVV EC of Rasa ${ }^{f l f l} C d h 5^{\text {ert2cre }}$ embryos, green fluorescence signals should be visibly absent in regions of the cell that contain large intracellular accumulations of collagen IV, i.e. in the ER.As shown in Figure 5 and Supplemental Figure 2, in LVV of Rasa ${ }^{f l f l}$ $C d h 5^{\text {ert2cre }}$ embryos, individual LVV EC could be identified that contained large accumulations of collagen IV that displaced the cytoplasmic eGFP signal. No such accumulations of collagen IV were identified in LVV EC of Rasal $1^{f l f l}$ embryos (Figure 5).

\section{Rescue of LVV development by a chemical chaperone that promotes folding of}

collagen IV. Collagen IV becomes trapped in the ER of RASA1-deficient EC as a consequence of impaired collagen IV folding. Accordingly, 4PBA, a chemical chaperone that promotes folding of collagen IV in the ER, ${ }^{31,32}$ rescues EC export of collagen IV and EC apoptosis. ${ }^{19}$ Therefore, we examined if 4PBA could rescue LVV and central VV development in the absence of RASA1. 4PBA was administered along with TM to 
Rasal $1^{f l f l}$ and Rasa1 $1^{f l f l} C_{d h 5^{\text {ert2cre }}}$ embryos at E12.5 and on all subsequent days until embryo harvest at E16.5. 4PBA rescued LVV development in these experiments (Figure $6 \mathrm{~A}$ and B). In TM plus 4PBA-treated Rasa ${ }^{f l f l} C d h 5^{\text {ert2cre }}$ embryos, approximately half of examined LV-BV junctions contained one LVV and the remaining half contained two LVV (compared to no LVV in the majority of LV-BV junctions in Rasa ${ }^{f l f l}$ Cdh $^{\text {ert2cre }}$ embryos that received TM alone). No influence of 4PBA upon LVV development was noted in TM-treated Rasa ${ }^{f l f l}$ embryos (Figure 6 A and B). In addition, 4PBA partially rescued development of the EJV VV although was unable to rescue development of the IJV and SCV VV (Figure $6 \mathrm{~A}$ and $\mathrm{C}$ ). These findings provide support for the idea that impaired development of LVV and, in part, the EJV VV is a consequence of an inability of EC to export collagen IV for deposition in the ECM core of the respective valve leaflets. Consistent with this, close inspection of 4PBA-rescued LVV revealed normal export of collagen IV by LVV EC and deposition in the LVV ECM core (Figure 6 D).

\section{Rescue of LVV development by an inhibitor of collagen IV modifying enzymes.}

Folding of two alpha 1 and one alpha 2 collagen IV monomers into a triple helical protomer conformation in the ER is a highly regulated process that requires multiple post-translational modifications of monomers mediated by protein disulphide isomerases (PDIs), protein peptidyl isomerases (PPIs), proline-3 and proline-4 hydroxylases (P3H1-3 and P4HA1-3 respectively) and lysine hydroxylases and glycosylases (procollagenlysine, 2-oxoglutarate 5-dioxygenases - PLODs 1-3). ${ }^{33-36}$ Under- or over-posttranslational modification of collagen IV monomers can affect folding of monomers into the triple helical conformation. Proteomic analyses of induced RASA1-deficient 
embryonic BEC established that of the P3H, P4HA and PLOD enzymes that could be detected in these cells ( 7 out of a total of 9 ), all were increased in abundance compared to control RASA1-sufficient BEC. ${ }^{19}$ P3Hs, P4HAs and PLODs all belong to the same family of enzymes known as 2-oxoglutarate (2OG)-dependent oxygenases (2OG-DO) and, consequently, can be collectively inhibited by drugs such as 2,4 pyridinedicarboxylic acid (2,4 PDCA). ${ }^{37,38}$ Consistent with the notion that increased abundance of 2OG-DO in embryonic RASA1-deficient BEC is responsible for the impaired folding and export of collagen IV, 2, 4 PDCA rescued collagen IV retention and BEC apoptosis in induced global RASA1-deficient embryos. ${ }^{19}$ Based on these findings, we asked if 2,4 PDCA could also rescue LVV and VV development in the absence of RASA1. As in previous drug rescue experiments, 2,4 PDCA was administered with TM to E12.5 Rasa $^{f l / f l}$ and Rasal ${ }^{f l f l} C_{d h 5^{\text {ert2cre }}}$ embryos and on successive days thereafter until embryo harvest at E16.5 (Figure 7). 2,4 PDCA was able to rescue the impaired development of LVV in the absence of RASA1. Following drug treatment, the majority of LV-BV junctions contained 2 LVV (Figure 7 B). Furthermore, 2,4 PDCA restored export of collagen IV by LVV EC (Figure 7 D). In addition, 2,4 PDCA almost completely rescued VV development. Following drug treatment, the majority of examined BV junctions contained normal IJV, EJV and SCV VV (Figure 7 C).

\section{RASA1 is necessary for the maintenance of central venous valves in adults. To} determine if RASA1 is necessary for the maintenance of central VV in adults, we administered TM to adult littermate Rasal $1^{f l f l}$ and Rasa $1^{f l / f l} U b^{\text {ert2cre }}$ mice and examined VV function 3 months later. As a first approach, we examined central venous pressure 
that would be expected to be elevated in mice as a consequence of impaired VV function. ${ }^{39}$ Central venous pressure was monitored by telemetry throughout the 24-hour daily cycle for 6 days for each examined mouse (Figure 8 A). In these experiments Rasal $1^{f l f l} U b^{\text {ert2cre }}$ mice showed increased central venous pressure compared to Rasal ${ }^{f l f l}$ controls consistent with impaired VV function.

To examine central VV function directly, cervical veins were dissected from mice and VV function was tested in low pressure back-leak assays. In these assays, veins were trimmed to contain a single $\mathrm{VV}$ and were cannulated at both ends to allow manipulation of intraluminal pressure upstream $\left(\mathrm{P}_{\text {in }}\right)$ and downstream $\left(\mathrm{P}_{\text {out }}\right)$ of the valve. For back-leak assays, $\mathrm{P}_{\text {in }}$ was held constant at $0.5 \mathrm{~cm} \mathrm{H}_{2} \mathrm{O}$ and $\mathrm{P}_{\text {out }}$ was elevated over a physiological range from 0.5 to $10 \mathrm{~cm}$ of $\mathrm{H}_{2} \mathrm{O}$. The ability of valves to resist backflow in response to elevated pressure downstream of the valve was measured with the use of a servo null micropipette $\left(\mathrm{P}_{\mathrm{sn}}\right)$ inserted through the vessel wall into the upstream lumen (Figure $8 \mathrm{~B}$ ). Cervical VV from Rasal ${ }^{f l f l}$ mice were able to resist transfer of elevated downstream pressure to the upstream vessel lumen starting at around $4 \mathrm{~cm}$ of $\mathrm{H}_{2} \mathrm{O}$ (Figure $8 \mathrm{C}$ ). In contrast, cervical VV from Rasal $1^{f l f l} U b^{\text {ert2cre }}$ mice were unable to prevent backflow throughout the entire 0.5 to $10 \mathrm{~cm} \mathrm{H}_{2} 0$ range (Figure $8 \mathrm{C}$ ). Thus, cervical VV are functionally impaired in Rasal $1^{f l f l} U b^{\text {ert2cre }}$ mice.

Impaired LV valve function in adult induced RASA1-deficient mice is explained by reduced cellularity of LV valve leaflets resulting in shortening of leaflets and failed LV valve closure. ${ }^{20}$ Therefore, we examined the cellularity of cervical VV leaflets in 
induced RASA1-deficient and control mice. As determined with the use of the Prox1eGFP transgene, which allows ready identification and enumeration of VV EC, induced loss of RASA1 in adult mice resulted in significantly fewer EC in cervical VV leaflets compared to controls (Figure $8 \mathrm{D}$ and $\mathrm{E}$ ). Therefore, RASA1 is necessary to maintain numbers of EC in VV leaflets which accounts for impaired VV function in induced RASA1-deficient mice 


\section{Discussion}

In this study we show that RASA1 performs a non-redundant role in the development of LVV and the development and maintenance of VV. These findings extend our knowledge of the function of this RasGAP in both blood and lymphatic vascular systems. A role for RASA1 in the continued development of LVV and VV but not their initial specification parallels our earlier reported finding regarding the role of RASA1 in LV valve development. ${ }^{20} \mathrm{LVV}$ and VV development was also impaired in embryos in which RASA1 R780Q alone was expressed in EC. However, the impairment in LVV and VV development in these embryos was less than in embryos that lacked RASA1 in EC. This suggests that RASA1 regulates LVV and VV development through mechanisms that are independent of its GAP activity as well as mechanisms that are dependent upon its GAP activity. For LVV development, this is consistent with the finding that although a MAPK inhibitor was able to rescue valve development, rescue was incomplete. Moreover, for VV development, the same MAPK inhibitor was largely unable to rescue valve development in the absence of RASA1. Previously, we found that the RASA1 R780Q form of RASA1 was able to partially rescue the impaired function of adult LV valves resulting from induced loss of RASA $1 .{ }^{20}$ Thus, the time to development of LV valve dysfunction in adult mice induced to express RASA1 R780Q alone is substantially delayed compared to adult mice induced lose RASA1 completely. Which Rasindependent signaling pathways contribute to LVV and VV development and maintenance of mature LV valves remains to be determined. 
Abnormalities of LVV are first apparent at E15.5 following disruption of Rasa1 at E12.5. At this time, LEC and BEC layers of forming LVV detach from one another. In addition, intracellular accumulation of collagen IV can be detected in EC of valves at this time point. Intracellular accumulation of collagen IV is ultimately observed in all EC in which Rasal is disrupted prior to E15.5 and results in their apoptotic death, either as a result of anoikis (detachment from the substratum) or induction of an unfolded protein response. ${ }^{19}$ We propose that impaired export of collagen IV from EC of induced RASA1-deficient LVV, VV and LV valves is responsible for failed valve development. An inability of RASA1-deficient valve forming EC to export collagen IV for deposition in the developing ECM core of valves would be expected to result in EC detachment from the valve and/or induction of a UPR. Blocked export of collagen IV from RASA1-deficient embryonic EC and hemorrhage can be rescued by 4PBA that promotes folding of collagen IV in the ER. Similarly, in the current study, 4PBA largely rescued the impasse in LVV development and partially rescued the block in VV development in the absence of RASA1. These findings support the concept that collagen IV is retained within EC of developing RASA1-deficient LVV and VV because it is improperly folded. Our earlier proteomic studies of RASA1-deficient BEC identified increases in the abundance of all detectable collagen IV-modifying 2OG-DO enzymes in these cells. Evidence that this increase is responsible for collagen IV misfolding and retention in BEC was provided by the finding that drugs such as ethyl-3,4-dihydroxybenzoic acid (EDHB) and 2,4 PDCA, which broadly inhibit this class of enzymes, rescued collagen IV export from BEC and prevented hemorrhage. Similarly, as shown here, 2,4 PDCA rescued both LVV and VV development in the absence of RASA1. This is consistent with a model in which an 
increased abundance of 2OG-DO in EC of LVV and VV results in collagen IV retention in the ER, that in turn is responsible for blocked development of these valves in the absence of RASA1.

Induced loss of RASA1 in adult mice has not previously been reported to result in any spontaneous BV phenotypes. ${ }^{18}$ This can be explained on the grounds that deposition of collagen IV in BM primarily occurs during developmental angiogenesis. Collagen IV is an inherently stable molecule, thus obviating a requirement for $\mathrm{EC}$ to continue to engage in high rate collagen IV synthesis in postnatal life. ${ }^{40}$ A requirement of RASA1 for VV maintenance in adults represents an exception to this and parallels a requirement of RASA1 in the maintenance of LV valves in adults. ${ }^{20}$ Dysfunction of LV valves in induced RASA1-deficient mice can be explained by gradual loss of LEC from LV valve leaflets resulting in leaflet shortening below a threshold level necessary prevent to fluid backflow when closed leaflets overlap. Similarly, we show here that VV dysfunction is associated with reduced cellularity of VV leaflets. EC in LV valves and VV would be subject to higher shear stress forces than EC in LV and BV walls to the extent that continued high rate synthesis of collagen IV may be necessary for these cells to remain attached to the valve leaflet. ${ }^{41,42}$ Indeed, it is established that EC synthesize higher amounts of collagen IV when subject to shear stress in vitro. ${ }^{43}$ In this regard, induced loss of RASA1 in adult LV valve and VV EC may result in their detachment from leaflets or apoptotic death consequent to induction of a UPR, which may responsible for the leaflet shortening over time. 
Last, based upon the studies reported herein, it is conceivable that in CM-AVM, acquired somatic second hit mutations of the RASAl gene in LVV-forming and VV-forming cells or their precursors could result in impaired development and function of affected LVV and VV in these patients. Whether or not CM-AVM patients show abnormalities of LVV and VV function is currently unknown. 


\section{Methods}

Mice. Rasal $1^{f l f l}$ and Rasal $1^{f l / R 780 Q}$ mice with and without $U b^{\text {ert2cre }}$ transgenes have been described. ${ }^{16-18,20}$ Cdh5 ${ }^{\text {ert2cre }}$ mice were obtained from Cancer Research UK. ${ }^{29}$ ProxleGFP mice were obtained from Dr. Young Kwon Hong at the University of Southern California. Rasal $1^{f l f l} C d h 5^{\text {ert2cre }}$ and Rasal $1^{f l f l}$ Proxl-eGFP mice with and without $C d h 5^{\text {ert2cre }}$ and $U b^{\text {ert2cre }}$ were generated through cross-breeding. All mice were on a mixed 129S6/SvEv X C57BL/6 genetic background. All experiments performed with mice were in compliance with University of Michigan and University of Missouri guidelines and were approved by the respective university committees on the use and care of animals.

LVV and VV specification and development. Pregnant Rasal $1^{f l f l}$ mice carrying Rasal $1^{f l f l}$ embryos with and without $C d h 5^{\text {ert2cre }}$ and pregnant Rasal $1^{f l f R 780 Q}$ mice carrying Rasal ${ }^{f l f l}$, Rasal $1^{f l / R 780 Q}$ and Rasal $1^{R 780 Q / R 780 Q}$ embryos with and without and $U b^{\text {ert2cre }}$ were given 2 i.p. injections of TM as above on consecutive days starting at E10.5, E12.5 or E14.5 of gestation. For some pregnant mice, AZD6244 (Selleckchem; $0.05 \mathrm{mg} / \mathrm{g}$ body weight per injection), 4-phenylbutyric acid (4PBA; Sigma; $0.25 \mathrm{mg} / \mathrm{g}$ body weight per injection), or 2,4 PDCA (Sigma; $0.1 \mathrm{mg} / \mathrm{g}$ body weight per injection) was injected i.p. at the same time as TM and on subsequent days until embryo harvest. Embryos were harvested at different times and fixed in 4\% paraformaldehyde overnight. For embryos that were harvested at E14.5 and later, an abdominal incision was made and blood was drained from embryos before fixation. 
Immunohistochemistry on sections was performed as described.$^{22}$ Fixed embryos were embedded in OCT solution (Sakura, Tokyo, Japan) and $12 \mu \mathrm{m}$ thick cryosections were prepared in the frontal orientation using a cryotome (Thermo Fisher Scientific, Model: HM525 NX). Primary antibodies used were: goat anti-VEGFR3 (R\&D Systems), rabbit anti-PROX1 (AngioBio), rat anti-CD31 (BD Pharmingen), goat anti-collagen IV (134001, Southern Biotech), rabbit anti-pERK (D13.14.4E, Cell Signaling Technology). Secondary antibodies were fluorochrome-labeled species specific anti-Igs. The antibodies were diluted in blocking buffer (PBS+ $0.1 \%$ Triton $\mathrm{X}-100+0.1 \%$ BSA) and immunohistochemistry was performed using standard protocols. After mounting, the sections were visualized with Eclipse 80i microscope (Nikon, Tokyo, Japan) equipped with Zyla sCMOS camera (Andor Technology, Belfast, UK) and analyzed using NISElements BR software (Nikon, Tokyo, Japan). Several consecutive sections were analyzed to determine the presence or absence of LVVs and VVs.

SEM was performed according to our previous protocol. ${ }^{22,44}$ Briefly, $500 \mu \mathrm{m}$ sections were prepared using vibratome (Leica, Buffalo Grove, IL, USA). Sections were fixed in $2 \%$ glutaraldehyde in $0.1 \mathrm{M}$ cacodylate buffer for 2 hours. After washing profusely in $0.1 \mathrm{M}$ cacodylate buffer, the sections were post fixed in $1 \%$ osmium tetroxide in $0.1 \mathrm{M}$ cacodylate buffer for 2 hours and subsequently dehydrated in a graded ethanol series. The sections were further dehydrated in hexamethyldisilazane and allowed to air-dry overnight. Dry sections were sputter-coated with Au/Pd particles (Med-010 Sputter Coater by Balzers-Union, USA) and observed under Quanta SEM (FEI, Hillsboro, OR, USA) at an accelerating voltage of $20 \mathrm{KV}$. 
Central venous pressure. Three-month old littermate Rasal $1^{f l f l}$ and Rasal ${ }^{f l f l} U b^{\text {ert2cre }}$ mice were given 2 i.p. injections of TM $(0.05 \mathrm{mg} / \mathrm{g}$ body weight per injection, dissolved in corn oil) on consecutive days. One week later, central venous pressure was determined by radiotelemetry using an implantable microminiaturized electronic monitor (PA-C10; Data Sciences International) as described with minor modifications. ${ }^{45}$ Briefly, the catheter of the device was passed into the right EJV and the transducer was placed in the abdominal cavity. After surgery, mice were individually housed in cages atop receiver pads allowing for real-time measurements of venous pressure, heart rate and activity. To minimize the influence of fluctuations in venous pressure resulting from changes in respiration and activity, for each mouse an average central venous pressure was calculated based upon readings taken every 10 seconds for 15 minutes every 3 hours for 6 days total.

Vein dissection and cannulation. Three-month old littermate Rasa ${ }^{f l / f l}$ Proxl-eGFP mice with and without $U b^{\text {ert2cre }}$ were given 2 i.p. injections of TM as above. After 12 weeks, mice were anesthetized with sodium pentobarbital $(60 \mathrm{mg} / \mathrm{kg}$, i.p.) and placed on a heating pad. The skin under the chin and upper chest was shaved and a ventral incision was made to expose the underlying cervical and EJV in association with superior cervical afferent LV. The LV and attached connective tissue were removed and the EJV was cut centrally, held with fine forceps and pulled caudally while trimming along the sides of the vessel and its major branch, the cervical vein (and sometimes also other minor branches), until a segment $\sim 3-4 \mathrm{~mm}$ in length was obtained. Some vessels were unbranched (Figure $8 \mathrm{~B}$ ) but in most cases the cervical vein joined the external jugular 
vein just distal to the valve. After cutting the distal ends of the main vessel and any branches, the entire segment was removed and placed in room temperature Krebs-BSA solution [146.9 mM NaCl; $4.7 \mathrm{mM} \mathrm{KCl} ; 2 \mathrm{mM} \mathrm{CaCl}_{2} \cdot 2 \mathrm{H}_{2} \mathrm{O} ; 1.2 \mathrm{mM} \mathrm{MgSO} 4 ; 1.2 \mathrm{mM}$ $\mathrm{NaH}_{2} \mathrm{PO}_{4} \cdot \mathrm{H}_{2} \mathrm{O} ; 3 \mathrm{mM} \mathrm{NaHCO} 3 ; 1.5 \mathrm{mM}$ sodium-Hepes; $5 \mathrm{mM}$ D-glucose; $0.5 \%$ BSA $\left(\mathrm{pH} 7.4\right.$ at $\left.\left.37{ }^{\circ} \mathrm{C}\right)\right]$ in a dissection dish with a $1 \mathrm{~cm}$ layer of Sylgard (Dow Corning). The mouse was then euthanized with an injection of $\mathrm{KCl}(0.2 \mathrm{M}$, i.c. $)$. After pinning the segment with pieces of $40 \mu \mathrm{m}$ wire, the remaining connective tissue and fat were removed and the segment was transferred to a $3 \mathrm{ml}$ cannulation chamber. The proximal and distal ends were cannulated onto $90 \mu \mathrm{m}$ glass micropipettes filled with Krebs-BSA and tied with 12-0 suture. After pressurization most of the red blood cells were flushed out and any side branches were identified and tied with 12-0 suture. The cannulation chamber, with attached pipette holders and vessel, were transferred to the stage of an inverted microscope, where the segment was heated to $37^{\circ} \mathrm{C}$ and perfused with $\mathrm{Krebs}$ buffer $(0.5 \mathrm{ml} / \mathrm{min})$. Inflow and outflow pressures were set initially using standing fluid reservoirs and the axial length was adjusted to remove slack with luminal pressure briefly set to $10 \mathrm{cmH}_{2} \mathrm{O}$. The segment was then equilibrated for 30 minutes at $2 \mathrm{~cm} \mathrm{H}_{2} \mathrm{O}$ luminal pressure. Development of spontaneous tone confirmed vessel viability but the venous valve tests described below were performed after perfusion of the segment with $\mathrm{Ca}^{2+}$-free Krebs (Krebs with $3 \mathrm{mM}$ EDTA replacing $\mathrm{CaCl}_{2} \cdot 2 \mathrm{H}_{2} \mathrm{O}$ ) for at least 20 minutes to eliminate spontaneous tone. The vessel image was digitized using a fire-wire camera (model A641FM; Basler) and inner diameter was continuously tracked using a custom computer algorithm. ${ }^{46}$ All valve tests were recorded as AVI files, with embedded pressure and diameter data, for later replay and valve tracking, as needed. 
Valve back-leak assays. To conduct tests of valve function, the pressure control for each cannulation pipette was switched from the reservoirs to a two-channel pump controller (Cardiovascular Research Institute, Texas A\&M University) driven through a D-A interface by a LabVIEW program (National Instruments) running under Windows 7. A servo-nulling micropipette with tip diameter $\sim 3 \mu \mathrm{m}$ was inserted through the vessel wall on the upstream side of the valve to measure the local pressure (Psn) at that site. ${ }^{46}$ Psn, inflow pressure (Pin), outflow pressure (Pout) and diameter were recorded at $30 \mathrm{~Hz}$ using a model PCI 6030e A-D interface (National Instruments). After micropuncture Pin and Pout were raised simultaneously from 0.5 to $10 \mathrm{~cm} \mathrm{H}_{2} \mathrm{O}$ in order to verify the calibration of the servo-nulling system. To assess the ability of a closed valve to prevent pressure back leak, Pin was set to $0.5 \mathrm{~cm} \mathrm{H}_{2} \mathrm{O}$ and Pout was elevated ramp-wise from 0.5 to $10 \mathrm{~cm}$ $\mathrm{H}_{2} \mathrm{O}$ over a 2-min period. The servo-nulling pipette detected any rise in pressure upstream from the valve. The Pout ramp was repeated 3 times. For data analysis Psn and Pout values were binned in $1 \mathrm{~cm} \mathrm{H}_{2} \mathrm{O}$ intervals for each ramp, using a LabVIEW program, to obtain average values of Psn and Pout for plotting and statistical tests.

Venous valve whole mount staining. Vessels from VV function assays were fixed in $1 \%$ paraformaldehyde overnight, blocked by incubation in PBS $/ 10 \%$ donkey serum $/ 0.3 \%$ Triton-X100 and incubated overnight with rat anti-CD31 in PBS/10\% donkey serum $/ 0.3 \%$ Triton-X100. Vessels were subsequently incubated with donkey anti-rat Ig coupled to Alexa Fluor 594 (Jackson Immunoresearch) in PBS for 2 hours before 
bioRxiv preprint doi: https://doi.org/10.1101/2020.02.17.953364; this version posted May 1, 2020. The copyright holder for this preprint (which

was not certified by peer review) is the author/funder, who has granted bioRxiv a license to display the preprint in perpetuity. It is made available under aCC-BY-NC-ND 4.0 International license.

viewing on a Leica SP5 X confocal microscope. PROX1-positive EC in VV leaflets were enumerated with the use of Imaris software (Bitplane).

Statistical analysis. $P$ values were calculated using two-tailed Student's 2-sample 2sided $t$-testS. 


\section{References}

1 Buday, L. \& Downward, J. Many faces of Ras activation. Biochim Biophys Acta

1786, 178-187, doi:S0304-419X(08)00024-3 [pii]

10.1016/j.bbcan.2008.05.001 (2008).

2 Wennerberg, K., Rossman, K. L. \& Der, C. J. The Ras superfamily at a glance. J Cell Sci 118, 843-846 (2005).

3 Bos, J. L., Rehmann, H. \& Wittinghofer, A. GEFs and GAPs: critical elements in the control of small G proteins. Cell 129, 865-877 (2007).

4 Butler, J., Watson, H. R., Lee, A. G., Schuppe, H. J. \& East, J. M. Retrieval from the ER-golgi intermediate compartment is key to the targeting of c-terminally anchored ER-resident proteins. J Cell Biochem 112, 3543-3548, doi:10.1002/jcb.23281 (2011).

5 Rubinfeld, H. \& Seger, R. The ERK cascade: a prototype of MAPK signaling. Mol Biotechnol 31, 151-174, doi:10.1385/MB:31:2:151 (2005).

6 King, P. D., Lubeck, B. A. \& Lapinski, P. E. Nonredundant functions for Ras GTPase-activating proteins in tissue homeostasis. Sci Signal 6, re1, doi:scisignal.2003669 [pii]

10.1126/scisignal.2003669 (2013).

7 Eerola, I. et al. Capillary malformation-arteriovenous malformation, a new clinical and genetic disorder caused by RASA1 mutations. Am J Hum Genet 73, 1240-1249, doi:S0002-9297(07)63977-9 [pii]

$10.1086 / 379793(2003)$. 
8 Revencu, N. et al. RASA1 mutations and associated phenotypes in 68 families with capillary malformation-arteriovenous malformation. Hum Mutat 34, 16321641, doi:10.1002/humu.22431 (2013).

9 Revencu, N. et al. Parkes Weber syndrome, vein of Galen aneurysmal malformation, and other fast-flow vascular anomalies are caused by RASA1 mutations. Hum Mutat 29, 959-965 (2008).

10 Lapinski, P. E. et al. Somatic second hit mutation of RASA1 in vascular endothelial cells in capillary malformation-arteriovenous malformation. Eur $J$ Med Genet 61, 11-16, doi:10.1016/j.ejmg.2017.10.004 (2018).

11 Macmurdo, C. F. et al. RASA1 somatic mutation and variable expressivity in capillary malformation/arteriovenous malformation (CM/AVM) syndrome. Am J Med Genet A 170, 1450-1454, doi:10.1002/ajmg.a.37613 (2016).

12 Burrows, P. E. et al. Lymphatic abnormalities are associated with RASA1 gene mutations in mouse and man. Proc Natl Acad Sci U S A, doi:1222722110 [pii]

10.1073/pnas.1222722110(2013).

13 de Wijn, R. S. et al. Phenotypic variability in a family with capillary malformations caused by a mutation in the RASA1 gene. Eur J Med Genet 55, 191-195, doi:S1769-7212(12)00029-8 [pii]

10.1016/j.ejmg.2012.01.009 (2012).

14 Sevick-Muraca, E. M. \& King, P. D. Lymphatic vessel abnormalities arising from disorders of Ras signal transduction. Trends Cardiovasc Med 24, 121-127, doi:10.1016/j.tcm.2013.09.004 (2014). 
15 Henkemeyer, M. et al. Vascular system defects and neuronal apoptosis in mice lacking ras GTPase-activating protein. Nature 377, 695-701 (1995).

16 Lubeck, B. A. et al. Blood vascular abnormalities in Rasa1(R780Q) knockin mice: implications for the pathogenesis of capillary malformation-arteriovenous malformation. Am J Pathol 184, 3163-3169, doi:10.1016/j.ajpath.2014.08.018 (2014).

17 Lapinski, P. E. et al. Generation of mice with a conditional allele of the p120 Ras GTPase-activating protein. Genesis 45, $762-767$ (2007).

18 Lapinski, P. E. et al. RASA1 maintains the lymphatic vasculature in a quiescent functional state in mice. J Clin Invest 122, 733-747, doi:46116 [pii]

10.1172/JCI46116 (2012).

19 Chen, D., Teng, J. M., North, P. E., Lapinski, P. E. \& King, P. D. RASA1dependent cellular export of collagen IV controls blood and lymphatic vascular development. J Clin Invest 130, 3545-3561, doi:10.1172/JCI124917 (2019).

20 Lapinski, P. E. et al. RASA1 regulates the function of lymphatic vessel valves in mice. J Clin Invest 127, 2569-2585, doi:10.1172/JCI89607 (2017).

21 Sabine, A. et al. Mechanotransduction, PROX1, and FOXC2 cooperate to control connexin37 and calcineurin during lymphatic-valve formation. Developmental cell 22, 430-445, doi:S1534-5807(11)00586-7 [pii]

10.1016/j.devcel.2011.12.020 (2012).

22 Geng, X. et al. Multiple mouse models of primary lymphedema exhibit distinct defects in lymphovenous valve development. Dev Biol 409, 218-233, doi:10.1016/j.ydbio.2015.10.022 (2016). 
23 Srinivasan, R. S. \& Oliver, G. Prox1 dosage controls the number of lymphatic endothelial cell progenitors and the formation of the lymphovenous valves. Genes Dev 25, 2187-2197, doi:10.1101/gad.16974811(2011).

24 Geng, X., Cha, B., Mahamud, M. R. \& Srinivasan, R. S. Intraluminal valves: development, function and disease. Dis Model Mech 10, 1273-1287, doi:10.1242/dmm.030825 (2017).

25 Meissner, M. H. et al. Secondary chronic venous disorders. J Vasc Surg 46 Suppl S, 68S-83S, doi:10.1016/j.jvs.2007.08.048 (2007).

26 Meissner, M. H. et al. Primary chronic venous disorders. J Vasc Surg 46 Suppl S, 54S-67S, doi:10.1016/j.jvs.2007.08.038 (2007).

27 Munger, S. J. et al. Segregated Foxc2, NFATc1 and Connexin expression at normal developing venous valves, and Connexin-specific differences in the valve phenotypes of Cx37, Cx43, and Cx47 knockout mice. Dev Biol 412, 173-190, doi:10.1016/j.ydbio.2016.02.033 (2016).

28 Bazigou, E. et al. Genes regulating lymphangiogenesis control venous valve formation and maintenance in mice. J Clin Invest 121, 2984-2992, doi:58050 [pii] 10.1172/JCI58050 (2011).

29 Wang, Y. et al. Ephrin-B2 controls VEGF-induced angiogenesis and lymphangiogenesis. Nature 465, 483-486, doi:10.1038/nature09002 (2010).

30 Choi, I. et al. Visualization of lymphatic vessels by Prox1-promoter directed GFP reporter in a bacterial artificial chromosome-based transgenic mouse. Blood 117, 362-365, doi:blood-2010-07-298562 [pii]

10.1182/blood-2010-07-298562 (2011). 
31 Jeanne, M., Jorgensen, J. \& Gould, D. B. Molecular and Genetic Analyses of Collagen Type IV Mutant Mouse Models of Spontaneous Intracerebral Hemorrhage Identify Mechanisms for Stroke Prevention. Circulation 131, 15551565, doi:10.1161/CIRCULATIONAHA.114.013395 (2015).

32 Kuo, D. S. et al. Allelic heterogeneity contributes to variability in ocular dysgenesis, myopathy and brain malformations caused by Col4a1 and Col4a2 mutations. Hum Mol Genet 23, 1709-1722, doi:10.1093/hmg/ddt560 (2014).

33 Mao, M., Alavi, M. V., Labelle-Dumais, C. \& Gould, D. B. Type IV Collagens and Basement Membrane Diseases: Cell Biology and Pathogenic Mechanisms. Curr Top Membr 76, 61-116, doi:10.1016/bs.ctm.2015.09.002 (2015).

34 Chioran, A., Duncan, S., Catalano, A., Brown, T. J. \& Ringuette, M. J. Collagen IV trafficking: The inside-out and beyond story. Dev Biol 431, 124-133, doi:10.1016/j.ydbio.2017.09.037 (2017).

35 Ishikawa, Y. \& Bachinger, H. P. A molecular ensemble in the rER for procollagen maturation. Biochim Biophys Acta 1833, 2479-2491, doi:10.1016/j.bbamcr.2013.04.008 (2013).

36 Ricard-Blum, S. The collagen family. Cold Spring Harb Perspect Biol 3, a004978, doi:10.1101/cshperspect.a004978 (2011).

37 Gilkes, D. M. et al. Collagen prolyl hydroxylases are essential for breast cancer metastasis. Cancer Res 73, 3285-3296, doi:10.1158/0008-5472.CAN-12-3963 (2013). 
38 Rose, N. R., McDonough, M. A., King, O. N., Kawamura, A. \& Schofield, C. J. Inhibition of 2-oxoglutarate dependent oxygenases. Chem Soc Rev 40, 4364-4397, doi:10.1039/c0cs00203h (2011).

39 Eberhardt, R. T. \& Raffetto, J. D. Chronic venous insufficiency. Circulation 130, 333-346, doi:10.1161/CIRCULATIONAHA.113.006898 (2014).

40 Shoulders, M. D. \& Raines, R. T. Collagen structure and stability. Annu Rev

Biochem 78, 929-958, doi:10.1146/annurev.biochem.77.032207.120833 (2009).

41 Bazigou, E. \& Makinen, T. Flow control in our vessels: vascular valves make sure there is no way back. Cell Mol Life Sci 70, 1055-1066, doi:10.1007/s00018-0121110-6 (2013).

42 Bazigou, E., Wilson, J. T. \& Moore, J. E., Jr. Primary and secondary lymphatic valve development: molecular, functional and mechanical insights. Microvasc Res 96, 38-45, doi:10.1016/j.mvr.2014.07.008 (2014).

43 Yamane, T. et al. Laminar high shear stress up-regulates type IV collagen synthesis and down-regulates MMP-2 secretion in endothelium. A quantitative analysis. Cell Tissue Res 340, 471-479, doi:10.1007/s00441-010-0968-6 (2010).

44 Geng, X. \& Srinivasan, R. S. Correlative Fluorescence and Scanning Electron Microscopy to Study Lymphovenous Valve Development. Methods Mol Biol 1846, 85-96, doi:10.1007/978-1-4939-8712-2_6(2018).

45 Whitesall, S. E., Hoff, J. B., Vollmer, A. P. \& D'Alecy, L. G. Comparison of simultaneous measurement of mouse systolic arterial blood pressure by radiotelemetry and tail-cuff methods. Am J Physiol Heart Circ Physiol 286, H2408-2415, doi:10.1152/ajpheart.01089.2003 (2004). 
46 Davis, M. J., Rahbar, E., Gashev, A. A., Zawieja, D. C. \& Moore, J. E., Jr.

Determinants of valve gating in collecting lymphatic vessels from rat mesentery.

Am J Physiol Heart Circ Physiol 301, H48-60, doi:10.1152/ajpheart.00133.2011

(2011). 
Acknowledgements We acknowledge the assistance of the Michigan Medicine

Physiology Phenotyping Core for measurement of central venous pressure in mice.

This work was supported by National Institutes of Health grants HL120888 and

HL146352 to PDK, HL131652 and HL133216 to SS, HL-120867 to MJD and

GM103441 to XG (PI: Dr. McEver).

Author contributions All authors designed experiments and analyzed data; D.C., X.G.

P.E.L. and M.J.D. conducted experiments; P.D.K. wrote the manuscript with input from other authors.; P.D.K. supervised the project.

Disclosures. None. 


\section{Figure Legends}

Figure 1. RASA1 is not required for the specification of LVV and central VV. A and $\mathbf{B}$, Rasa1 $1^{f l f l}$ and Rasa1 $1^{f l f l} C_{d h 5^{\text {ert2cre }}}$ embryos were administered TM at E10.5 or E12.5 and harvested at E12.5 or E14.5 respectively. Longitudinal sections through the neck region were stained with the indicated antibodies. LS, lymphatic sac; IJV, internal jugular vein; SVC, superior vena cava. LVV are indicated by arrows and VV by arrowheads. Note normal specification of LVV at E12.5 and VV at E14.5 (n=2 and 5 Rasal $^{f l f f l}$ and Rasa ${ }^{f l / f l}$ $C d h 5^{\text {ert2cre }}$ embryos respectively at E12.5 and n=4 and 5 Rasa ${ }^{f l f l}$ and Rasal ${ }^{f l f l}$ Cdh $^{\text {ert2cre }}$ embryos respectively at E14.5.

Figure 2. RASA1 is necessary for continued LVV and central VV development after initial specification. A and B, Rasal $I^{f l f l}$ and Rasal ${ }^{f l f l} C d h 5^{\text {ert2cre }}$ embryos were administered TM at E12.5 and harvested at E16.5. A, Longitudinal sections through the neck region (dorsal to ventral from top to bottom) were stained with the indicated antibodies. LS, lymphatic sac; IJV, internal jugular vein; EJV, external jugular vein; SCV, subclavian vein; SVC, superior vena cava. LVV and VV are indicated by arrows and arrowheads respectively. B, The structure of LVV and central VV was analyzed by SEM. A, Artery. LVV and VV are pseudo-colored in magenta and green respectively. In A and $\mathbf{B}$, note absence of LVV and VV in Rasal ${ }^{\text {flfl }} \mathrm{Cdh}^{\text {ert2cre }}$ embryos. C, Percentage of LV-BV junctions from Rasa $1^{f l / f l}$ and Rasa $1^{f l / f l} C d h 5^{\text {ert2cre }}$ embryos in $\mathbf{A}$ and $\mathbf{B}$ that contain the indicated number of LVV. Rasal $I^{f l f l} \mathrm{n}=11$, Rasa $1^{f l / f l} \operatorname{Cdh}^{\text {ert2cre }} \mathrm{n}=13$. D, VV structure categories. E, Percentage of BV junctions for Rasal $1^{f l f l}$ and Rasal $1^{f l f l} C_{d h 5^{\text {ert2cre }}}$ embryos 
in $\mathbf{A}$ and $\mathbf{B}$ that fall into the indicated VV categories in $\mathbf{D}$. Rasal $1^{f l f l} \mathrm{n}=11$, Rasa $^{f l f f l}$ $\operatorname{Cdh} 5^{\text {ert2cre }} \mathrm{n}=13$.

Figure 3. Development of LVV and central VV in RASA1 R780Q embryos. A, Rasal $1^{f l / R 780 Q}$ females were crossed with Rasal $1^{f l / R 780 Q} U b^{\text {ert2cre }}$ males. TM was administered to pregnant females at E12.5 and embryos were harvested at E16.5. Longitudinal sections of the neck region (dorsal to ventral from top to bottom) were stained with the indicated antibodies. Shown are representative images from Rasal $1^{f l / R 780 Q}$ and Rasal $1^{f l / R 780 Q} U b^{\text {ert2cre }}$ embryos. LS, lymphatic sac; IJV, internal jugular vein; EJV, external jugular vein; SCV, subclavian vein; SVC, superior vena cava. Arrows and arrowheads indicate LVV and VV respectively. B and C, Percentage of LV-BV junctions from Rasal $1^{f l / R 780 Q} U b^{\text {ert2cre }}$ embryos and control Rasal $1^{f l f l}$ and Rasal $1^{f l / R 780 Q}$ embryos from A that contain the indicated number of LVV (B) and categories of VV (C, see Figure 2 D). Rasa $1^{f l / R 780 Q} U b^{\text {ert2cre }} \mathrm{n}=6$, Rasal $^{f l / f l}$ plus Rasal ${ }^{f l / R 780 Q} \mathrm{n}=8$.

Figure 4. MAPK activation in LVV and effect of MAPK inhibition upon LVV and VV development in induced EC-specific RASA1-deficient embryos. A, Rasal ${ }^{f l f f l}$ and Rasal ${ }^{f l / f l}$ $C d h 5^{\text {ert2cre }}$ embryos were administered TM at E12.5 and embryos were harvested at E14.5. Longitudinal sections through the neck region were stained with the indicated antibodies. Representative sections show an increased number of EC in LVV of Rasa flffl $C d h 5^{\text {ert2cre }}$ embryos with activated phospho-ERK MAPK (pERK) (arrows). LS, lymphatic sac; SVC, superior vena cava. B, Mean +1 SEM of the number of pERK+ EC in LVV of embryos of the indicated genotypes $(\mathrm{n}=3) . *, P<0.05$, Student's 2-sample t-test. $\mathbf{C}$, 
Rasal $1^{f l f l}$ and Rasal ${ }^{f l f l}$ Cdh5 $5^{\text {ert2cre }}$ embryos were administered TM and AZD6244 at E12.5 and AZD6244 every day thereafter until embryo harvest at E16.5. Longitudinal sections through the neck region (dorsal to ventral from top to bottom) were stained with the indicated antibodies. D and E, Percentage of LV-BV junctions from Rasa $1^{f l f l}$ and Rasa $1^{f l f l} C d h 5^{\text {ert2cre }}$ embryos from $\mathbf{C}$ that contain the indicated number of LVV (D) and categories of VV (E, see Figure 2 D). Rasal ${ }^{f l f l} \mathrm{n}=4$, Rasal $^{f l f l} \operatorname{Cdh}^{\text {ert2cre }} \mathrm{n}=12$. Note that data from Rasal $1^{f l f l}$ and Rasal ${ }^{f l f l} C d h 5^{\text {ert2cre }}$ embryos treated with TM alone from Figure 2 $\mathrm{C}$ and $\mathrm{E}$ (red and black bars) is also plotted for comparison.

Figure 5. Accumulation of collagen IV in EC of developing RASA1-deficient LVV. Rasal $1^{\text {flfl }}$ Proxl-eGFP and Rasal ${ }^{\text {flfl }}$ Cdh5 $5^{\text {ert2cre }}$ Proxl-eGFP embryos were administered $\mathrm{TM}$ at E12.5 and harvested at E15.5. Longitudinal sections through the neck region were stained with antibodies against collagen IV and the Hoechst nuclear stain. Lower power images of LVV are shown at top. Higher power images of boxed areas are shown below. LS, lymphatic sac. Note intracellular accumulation of collagen IV that corresponds to regions of displacement of the eGFP signal in EC of Rasal $1^{f l f l}$ Cdh $5^{\text {ert2cre }}$ LVV (arrows). Additional images of collagen IV accumulation in EC of LVV of Rasal ${ }^{\text {flfl } l} C d h 5^{\text {ert2cre }}$ embryos are provided in Supplemental Figure 2.

Figure 6. Rescue of LVV Development in induced EC-specific RASA1-deficient embryos by the chemical chaperone 4PBA. A-D, Rasal $1^{f l f l}$ and Rasa $1^{f l / f l} C_{d h 5^{\text {ert2cre }}}$ embryos were administered TM and 4PBA at E12.5 and 4PBA every day thereafter until embryo harvest at E16.5. Longitudinal sections of the neck region (dorsal to ventral from 
top to bottom) were stained with the indicated antibodies. LS, lymphatic sac; IJV, internal jugular vein; EJV, external jugular vein; SCV, subclavian vein; SVC, superior vena cava. In (A) arrows and arrowheads indicate LVV and VV respectively. $\mathbf{B}$ and $\mathbf{C}$, Percentage of LV-BV junctions from Rasa $1^{f l / f l}$ and Rasa $1^{f l / f l} C d h 5^{\text {ert2cre }}$ embryos from (A) that contain the indicated number of LVV (B) and categories of VV (C, see Figure 2 D). Rasa fllfl $^{\text {I }}$ $\mathrm{n}=4$, Rasal ${ }^{f l f l} \operatorname{Cdh}^{\text {ert2cre }} \mathrm{n}=13$. Note that data from Rasal ${ }^{f l f l}$ and Rasal $1^{f l / f l} \operatorname{Cdh}^{\text {ert2cre }}$ embryos treated with TM alone from Figure $4 \mathrm{C}$ and $\mathrm{E}$ (red and black bars) is also plotted for comparison. D, Normal deposition of collagen IV in LVV of Rasa1 ${ }^{\text {flfl }}$ Cdh $^{\text {ert2cre }}$ embryos treated with 4PBA.

Figure 7. Rescue of LVV development in induced EC-specific RASA1-deficient embryos by 2,4 PDCA. A-D, Rasal ${ }^{f l f l}$ and Rasal $1^{f l f l} C d h 5^{\text {ert2cre }}$ embryos were administered TM and 2,4 PDCA at E12.5 and 2,4 PDCA every day thereafter until embryo harvest at E16.5. Longitudinal sections of the neck region (dorsal to ventral from top to bottom) were stained with the indicated antibodies. LS, lymphatic sac; IJV, internal jugular vein; EJV, external jugular vein; SCV, subclavian vein; SVC, superior vena cava. In (A) arrows and arrowheads indicate LVV and VV respectively. $\mathbf{B}$ and $\mathbf{C}$, Percentage of LV-BV junctions from Rasal $1^{f l f l}$ and Rasal $1^{f l f l} C d h 5^{\text {ert2cre }}$ embryos from (A) that contain the indicated number of LVV (B) and categories of VV (C, see Figure 2 D). Rasa fl/fl $\mathrm{n}=11, \operatorname{Rasal}^{\text {fllfl }} \operatorname{Cdh}^{\text {ert2cre }} \mathrm{n}=14$. Note that data from Rasal ${ }^{f l / f l}$ and Rasal ${ }^{\text {flffl }}$ Cdh $^{\text {ert2cre }}$ embryos treated with TM alone from Figure $2 \mathrm{C}$ and $\mathrm{E}$ (red and black bars) is also plotted for comparison. D, Normal deposition of collagen IV in LVV of Rasal ${ }^{\text {flflf }}$ Cdh $^{\text {ert2cre }}$ embryos treated with 2,4 PDCA. 
Figure 8. A required role for RASA1 in the maintenance of central VV function in adult mice. TM was administered to adult Rasal $1^{f l f l}$ and $R a s a 1^{f l f l} U b^{\text {ert2cre }}$ mice and central venous blood pressure was measured by telemetry 3 months later. At left is shown the mean +1 SEM of the central venous pressure for 3 individual mice of each genotype based upon continuous monitoring over 6 days (see Methods). At right is shown the mean +1 SEM of the mean central venous pressure of individual mice at left. ${ }^{*}, P<0.05$; Student's 2-sample t-test. B, Image of a dissected cervical vein from a Prox1-eGFP mouse showing positions of $\mathrm{P}_{\mathrm{in}}, \mathrm{P}_{\text {out }}$ and $\mathrm{P}_{\mathrm{sn}}$ micropipettes in low pressure back-leak assays (top) and the fluorescent eGFP positive VV (bottom). C, Low pressure back-leak tests of cervical VV from adult Rasa $1^{f l / f l}$ Proxl-eGFP and Rasa $1^{f l f l} U b^{\text {ert2cre }}$ Proxl-eGFP mice administered TM 3 months previously. Rasal $1^{f l f l}$ Proxl-eGFPn=9, Rasal ${ }^{f l f l} U^{\text {ert2cre }}$ Proxl-eGFP $\mathrm{n}=8$. Note leakage of Rasal ${ }^{f l f l} U b^{\text {ert2cre }}$ Proxl-eGFP valves throughout the $\mathrm{P}_{\text {out }}$ pressure range. $\mathbf{D}$, Whole mount images of representative cervical veins from Rasal ${ }^{f l f l}$ Proxl-eGFP and Rasa ${ }^{f l / f l} U^{\text {ert2cre }}$ Proxl-eGFP mice in C. Vessels were stained with an anti-CD31 antibody prior to mounting. E, Mean +1 SEM of the number of EC per VV leaflet. Rasal ${ }^{f l f l} \operatorname{Prox} 1-e G F P \mathrm{n}=8$, Rasal $^{f l / f l} U b^{\text {ert2cre }}$ Proxl-eGFPn=6. **, $P<0.01$, Student's 2-sample t-test.

Supplemental Figure 1. Abnormalities of LVV structure following induced loss of RASA1. Rasal $1^{f l f l}$ and Rasal $1^{f l f l} C d h 5^{\text {ert2cre }}$ embryos were administered TM at E12.5 and harvested at E15.5. Longitudinal sections through the neck region were stained with the indicated antibodies. LS, lymphatic sac; IJV, internal jugular vein; SCV, subclavian vein; 
SVC, superior vena cava. Note separation of EC layers of LVV in Rasa $f^{f l l f l} C d h 5^{\text {ert2cre }}$ embryos (arrows).

Supplemental Figure 2. Accumulation of collagen IV in EC of developing RASA1deficient LVV. Rasa ${ }^{f l / f l}$ Cdh $5^{\text {ert2cre }}$ Prox1-eGFP embryos were administered TM at E12.5 and harvested at E15.5. Longitudinal sections through the neck region were stained with antibodies against collagen IV and the Hoechst nuclear stain. Lower power images of LVV are shown at top. Higher power images of boxed areas are shown below. LS, lymphatic sac. Note intracellular accumulation of collagen IV that corresponds to regions of displacement of the eGFP signal in EC of LVV (arrows). 
A E10.5 TM - E12.5 analysis

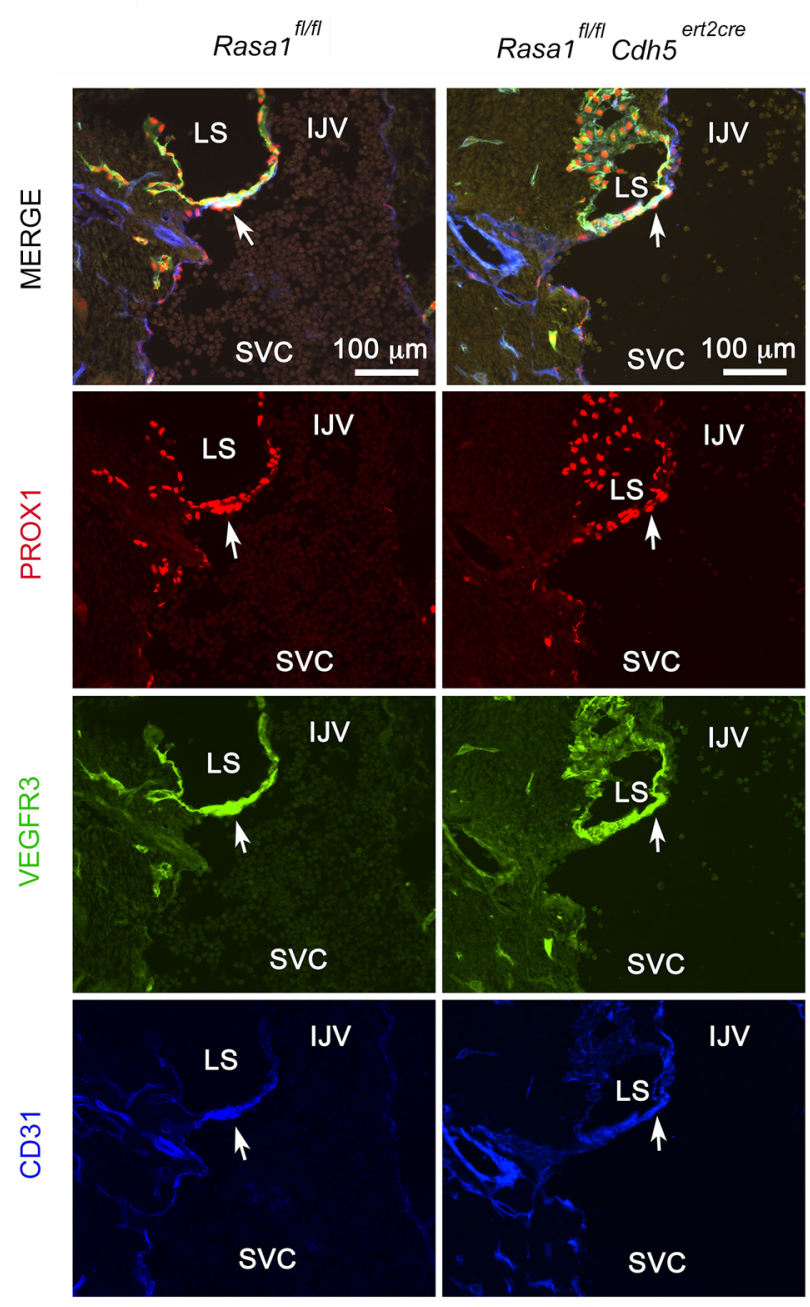

B E12.5 TM - E14.5 analysis

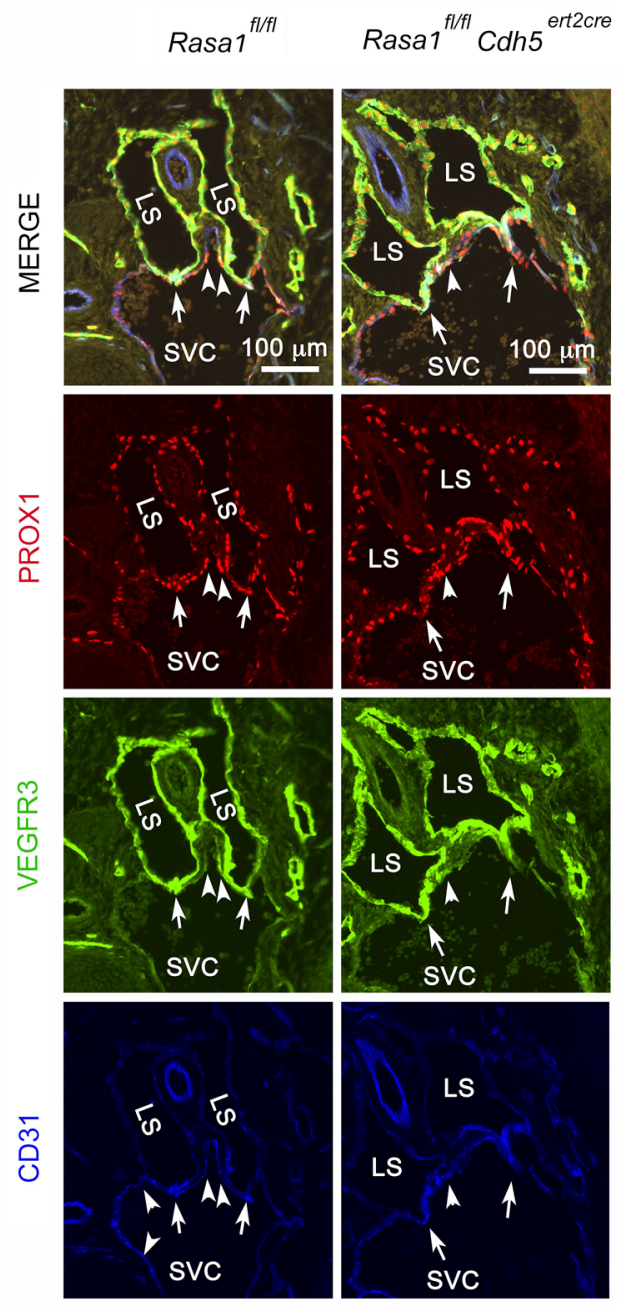

Figure 1. RASA1 is not required for the specification of LVV and central VV. A and B, Rasal ${ }^{\text {flfl }}$ and Rasal ${ }^{\text {fllfl }}$ Cdh $^{\text {ert2cre }}$ embryos were administered TM at E10.5 or E12.5 and harvested at E12.5 or E14.5 respectively. Longitudinal sections through the neck region were stained with the indicated antibodies. LS, lymphatic sac; IJV, internal jugular vein; SVC, superior vena cava. LVV are indicated by arrows and VV by arrowheads. Note normal specification of LVV at E12.5 and VV at E14.5 (n=2 and 5 Rasal ${ }^{f l f l}$ and Rasal $1^{f l f l} C_{d h 5^{\text {ert2cre }}}$ embryos respectively at E12.5 and $\mathrm{n}=4$ and 5 Rasal $^{\text {fl/fl }}$ and Rasal ${ }^{f l / f l}$ $C d h 5^{\text {ert2cre }}$ embryos respectively at E14.5. 
A

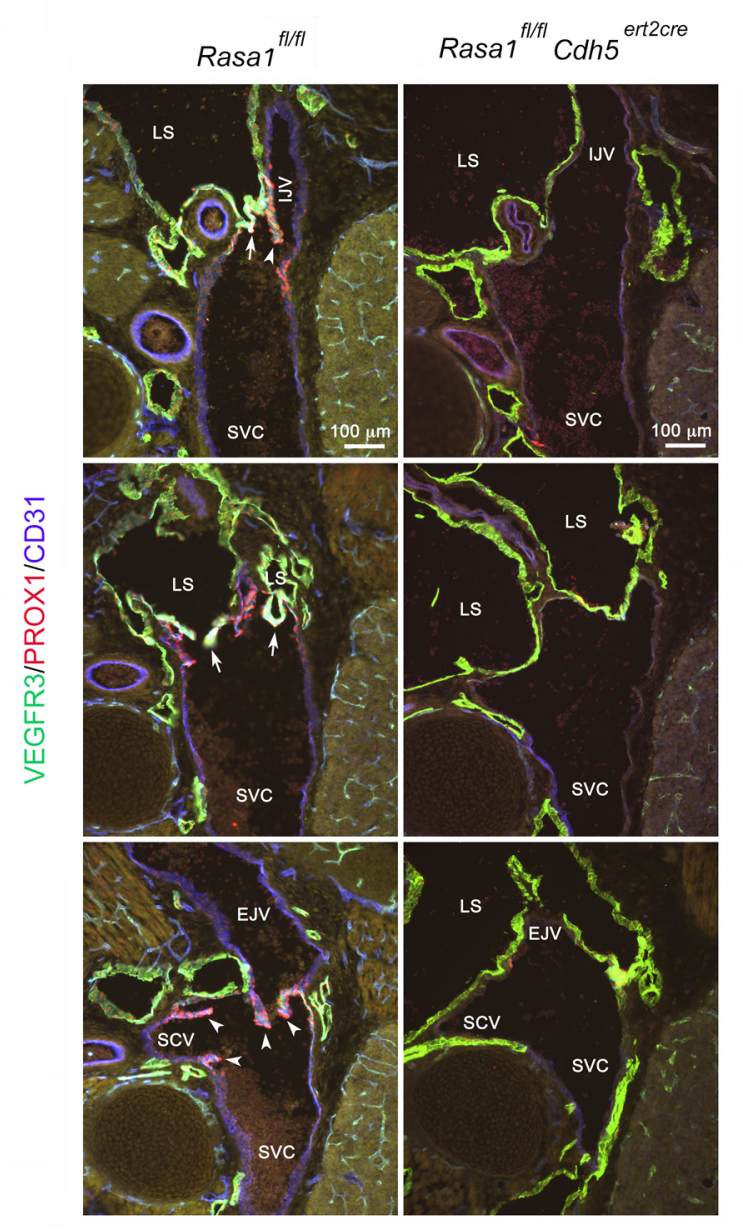

D

\begin{tabular}{|l|l|l|l|}
\hline & \multicolumn{3}{|l|}{ Venous valve } \\
\hline Category & SCV & IJV & EJV \\
\hline 1 & Absent & Absent & Absent \\
\hline 2 & Absent & Absent & Shortened \\
\hline 3 & Absent & Absent & Normal \\
\hline 4 & Shortened & Shortened & Shortened \\
\hline 5 & Normal & Normal & Normal \\
\hline
\end{tabular}

B E12.5 TM - E16.5 analysis

C Lymphovenous valves

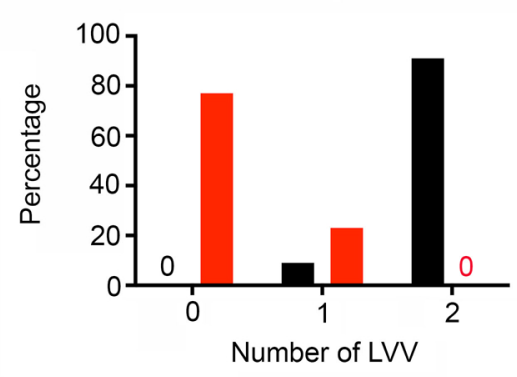

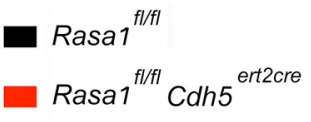

$E$

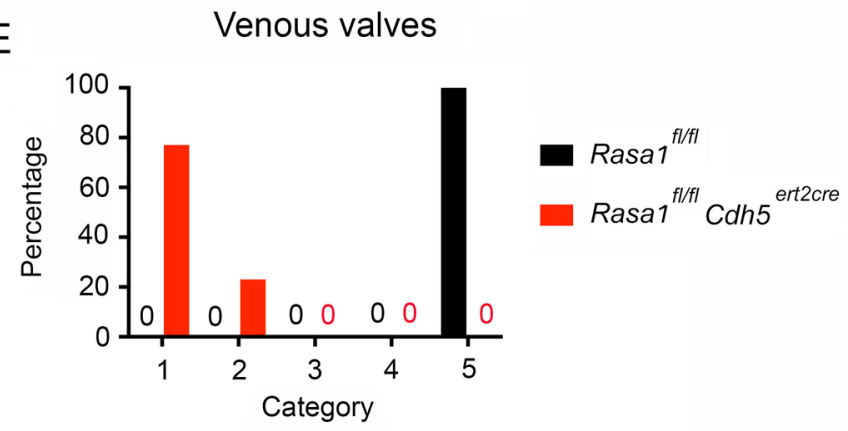

Figure 2. RASA1 is necessary for continued LVV and central VV development after initial specification. $\mathbf{A}$ and $\mathbf{B}$, Rasa $^{f l l f l}$ and Rasa $1^{f l / f l} C d h 5^{\text {ert } 2 c r e}$ embryos were administered TM at E12.5 and harvested at E16.5. A, Longitudinal sections through the neck region (dorsal to ventral from top to bottom) were stained with the indicated antibodies. LS, lymphatic sac; IJV, internal jugular vein; EJV, external jugular vein; SCV, subclavian vein; SVC, superior vena cava. LVV and VV are indicated by arrows and arrowheads respectively. $\mathbf{B}$, The structure of LVV and central VV was analyzed by SEM. A, Artery. LVV and VV are pseudo-colored in magenta and green respectively. In $\mathrm{A}$ and B, note absence of LVV and VV in Rasa $1^{f l f l} \mathrm{Cdh}^{\text {ertzcre }}$ embryos. C, Percentage of

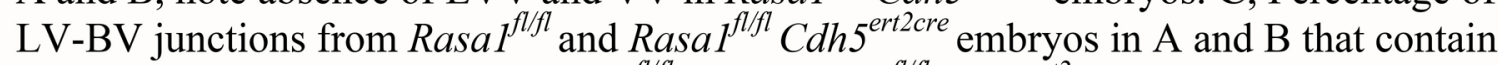
the indicated number of LVV. Rasal $1^{f l / f l} \mathrm{n}=11$, Rasa $I^{f l / f l} C_{d h 5^{\text {ert2cre }}} \mathrm{n}=13$. D, VV structure categories. E, Percentage of BV junctions for Rasal ${ }^{f l f l}$ and Rasal $I^{f l f l} C^{\prime} d h 5^{\text {ertzcre }}$ embryos in A and B that fall into the indicated VV categories in D. Rasa $f^{f l / f l} \mathrm{n}=11$, Rasa $f^{f l / f l}$ $\operatorname{Cdh}^{\text {ert2cre }} \mathrm{n}=13$. 
E12.5 TM - E16.5 analysis

A

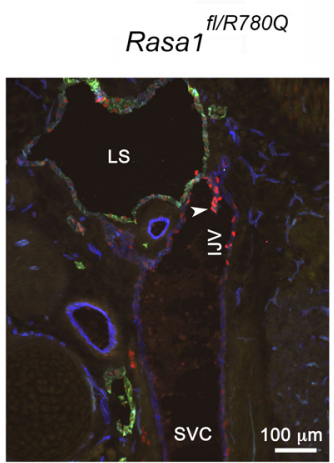

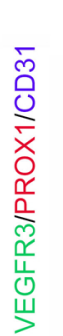
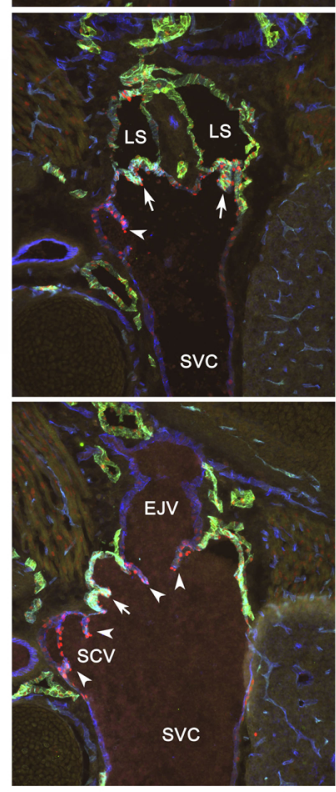

$\operatorname{Rasa1}^{\mathrm{fl} / \mathrm{R} 780 \mathrm{Q}} \mathrm{Ub} \mathrm{b}^{\mathrm{ert} 2 \mathrm{cre}}$
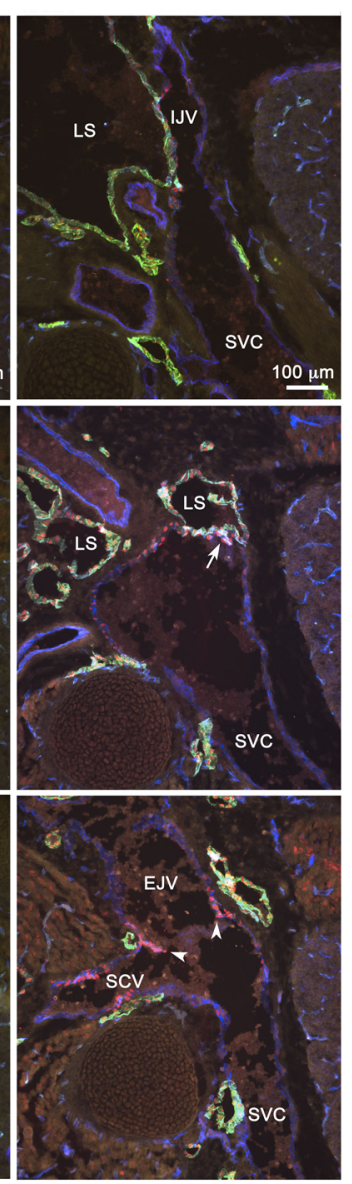

B

\section{Lymphovenous valves}

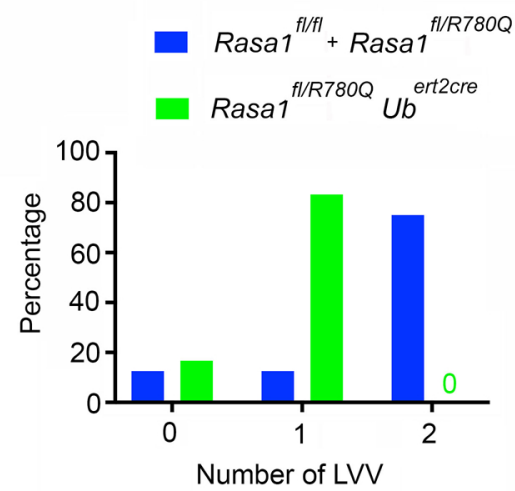

C
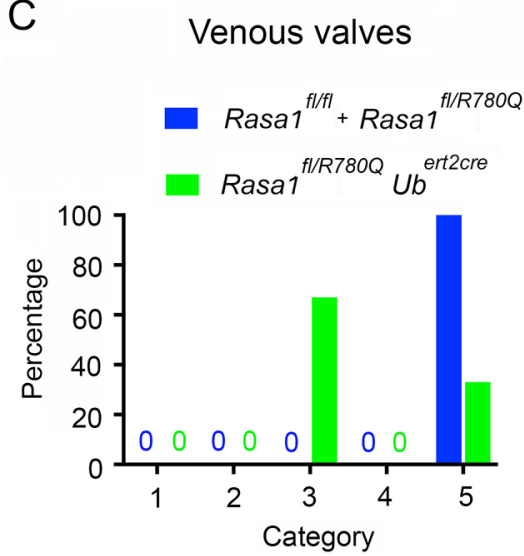

Figure 3. Development of LVV and central VV in RASA1 R780Q embryos. A, Rasal $1^{f l / R 780 Q}$ females were crossed with Rasal $1^{f l / R 780 Q} U b^{\text {ert2cre }}$ males. TM was administered to pregnant females at E12.5 and embryos were harvested at E16.5. Longitudinal sections of the neck region (dorsal to ventral from top to bottom) were stained with the indicated antibodies. Shown are representative images from Rasal $I^{f / R 780 Q}$ and Rasal $I^{f / R 780 Q} U^{\text {ert2cre }}$ embryos. LS, lymphatic sac; IJV, internal jugular vein; EJV, external jugular vein; SCV, subclavian vein; SVC, superior vena cava. Arrows and arrowheads indicate LVV and VV respectively. B and C, Percentage of LV-BV junctions from Rasa $1^{f / R 780 Q} U^{\text {ert2cre }}$ embryos and control Rasal $1^{f l / f l}$ and Rasal $1^{f l / R 780 Q}$ embryos from A that contain the indicated number of LVV (B) and categories of VV (C), see Figure 2 D). Rasal $1^{f / R 780 Q} U b^{\text {ert2cre }} \mathrm{n}=6$, Rasal $I^{f l f l}$ plus Rasal $1^{f l / R 780 Q} \mathrm{n}=8$. 
bioRxiv preprint doi: https://doi.org/10.1101/2020.02.17.953364; this version posted May 1, 2020. The copyright holder for this preprint (which was not certified by peer review) is the author/funder, who has granted bioRxiv a license to display the preprint in perpetuity. It is made E12.5 TM - E14.5 analysis

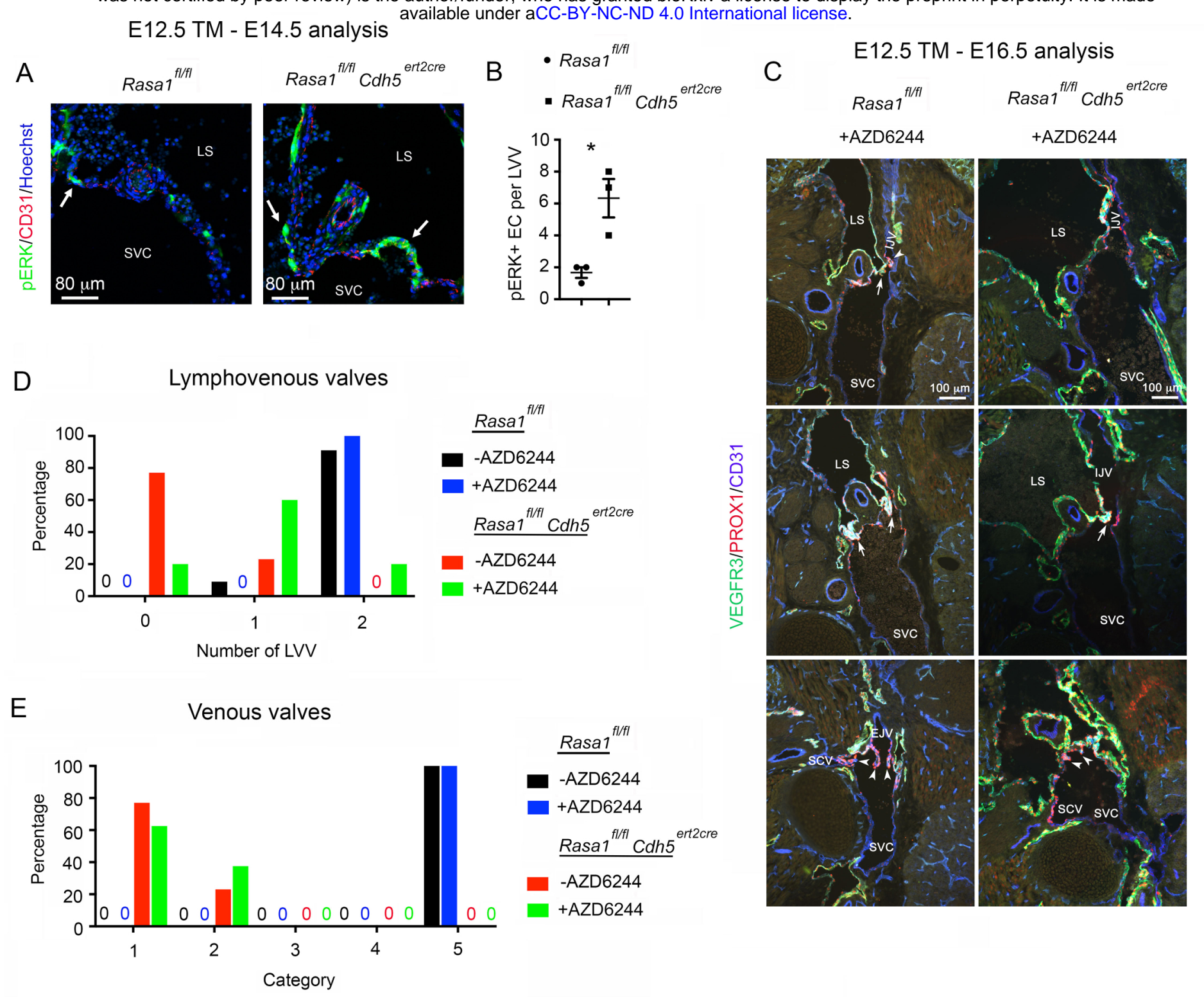
available under aCC-BY-NC-ND 4.0 International license.

Figure 4. MAPK activation in LVV and effect of MAPK inhibition upon LVV and VV development in induced EC-specific RASA1-deficient embryos. A, Rasa $f^{f l / f}$ and Rasa ${ }^{f l f l} \mathrm{Cdh}^{\text {ert2cre }}$ embryos were administered TM at E12.5 and embryos were harvested at E14.5. Longitudinal sections through the neck region were stained with the indicated antibodies. Representative sections show an increased number of EC in LVV of Rasa $1^{\text {fl/fl }}$ $C d h 5^{\text {ert2cre }}$ embryos with activated phospho-ERK MAPK (pERK) (arrows). LS, lymphatic sac; SVC, superior vena cava. B, Mean + 1 SEM of the number of pERK+ EC in LVV of embryos of the indicated genotypes $(\mathrm{n}=3)$. *, $P<0.05$, Student's 2 -sample t-test. $\mathbf{C}$, Rasal $I^{f l / l}$ and Rasal $I^{f l / f l} C d h 5^{\text {ertacre }}$ embryos were administered TM and AZD6244 at E12.5 and AZD6244 every day thereafter until embryo harvest at E16.5. Longitudinal sections through the neck region (dorsal to ventral from top to bottom) were stained with the indicated antibodies. D and E, Percentage of LV-BV junctions from Rasa $f^{f l f f}$ and Rasa ${ }^{\text {fllfl }} C d h 5^{\text {ert2cre }}$ embryos from C that contain the indicated number of LVV (D) and categories of VV (E, see Figure 2 D). Rasal $1^{f l f l} \mathrm{n}=4$, Rasa $1^{f / f l} C d h 5^{\text {ert2cre }} \mathrm{n}=12$. Note that data from Rasa $I^{f l / f l}$ and Rasa ${ }^{f l f l} C^{\prime} d h 5^{\text {ertzcre }}$ embryos treated with TM alone from Figure 2 $\mathrm{C}$ and $\mathrm{E}$ (red and black bars) is also plotted for comparison. 

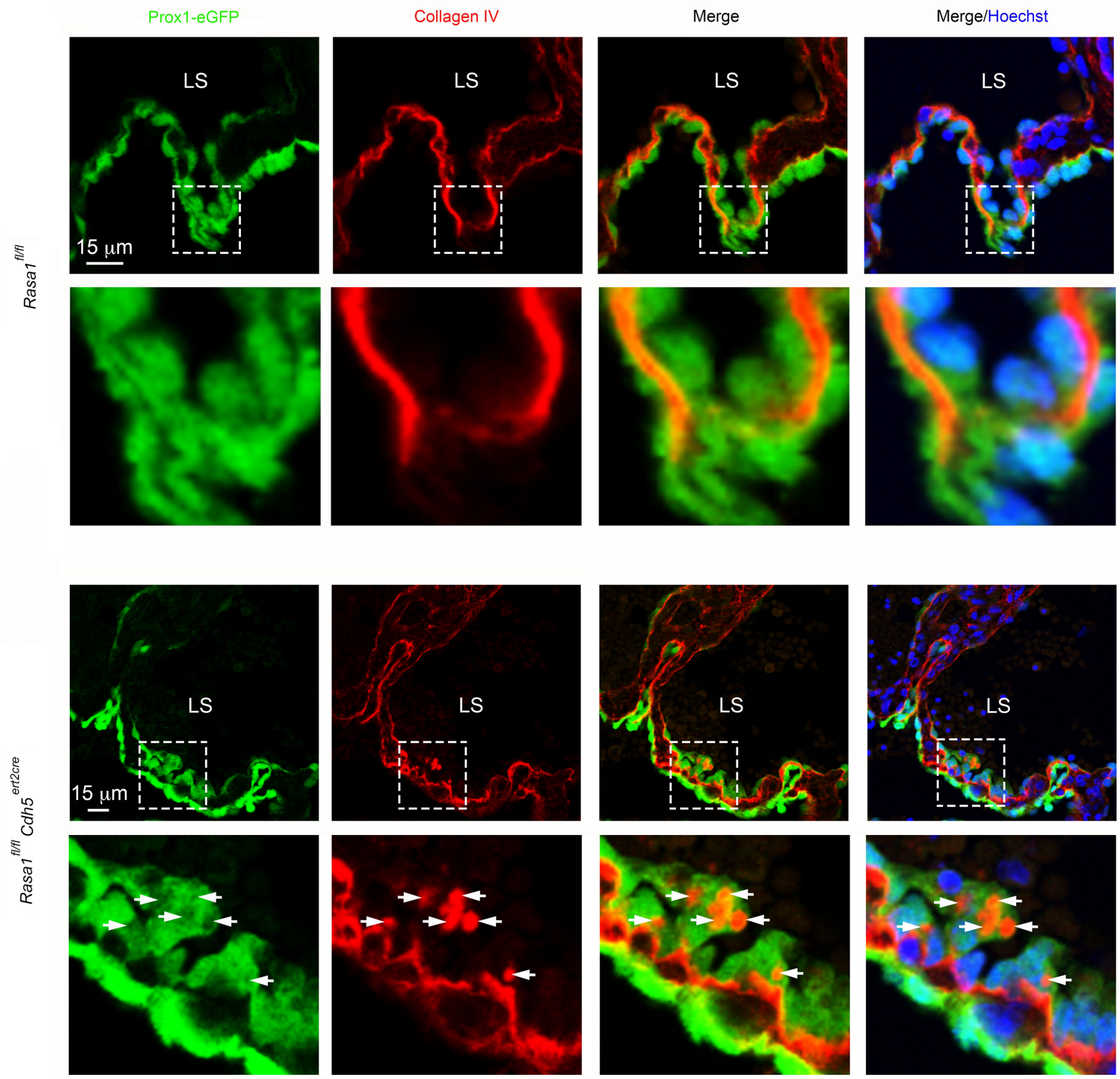

Figure 5. Accumulation of collagen IV in EC of developing RASA1-deficient LVV. Rasa $I^{\text {fllfl }}$ Proxl-eGFP and Rasa ${ }^{\text {flfll }}$ Cdh ${ }^{\text {ert2cre }}$ Proxl-eGFP embryos were administered $\mathrm{TM}$ at E12.5 and harvested at E15.5. Longitudinal sections through the neck region were stained with antibodies against collagen IV and the Hoechst nuclear stain. Lower power images of LVV are shown at top. Higher power images of boxed areas are shown below. LS, lymphatic sac. Note intracellular accumulation of collagen IV that corresponds to regions of displacement of the eGFP signal in EC of Rasa $1^{\text {flfl }}$ Cdh $5^{\text {ert2cre }}$ LVV (arrows). Additional images of collagen IV accumulation in EC of LVV of Rasal ${ }^{\text {flfl }} \mathrm{Cdh}^{\text {ert2cre }}$ embryos are provided in Supplemental Figure 2. 
E12.5 TM - E16.5 analysis

Rasa ${ }^{\text {flffl }}$

$+4 \mathrm{PBA}$
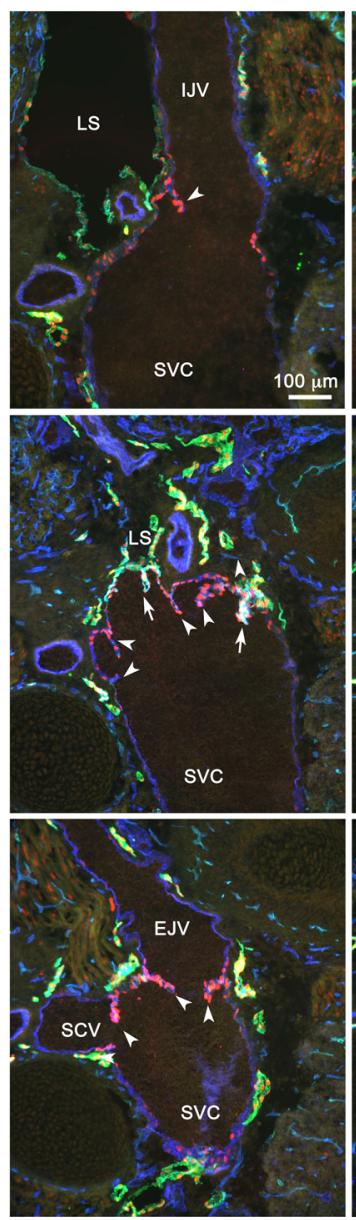

Rasa $1^{\text {fl/fl }} \mathrm{Cdh} 5^{\text {ert2cre }}$

$+4 \mathrm{PBA}$

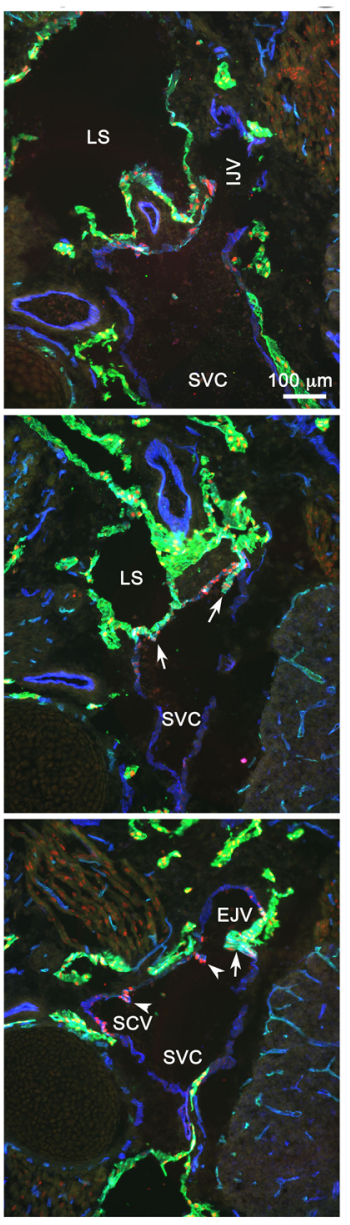

B

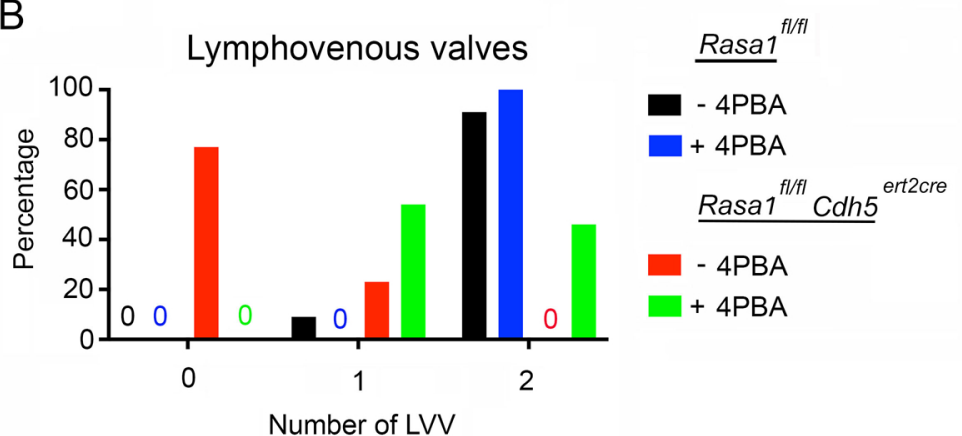

C

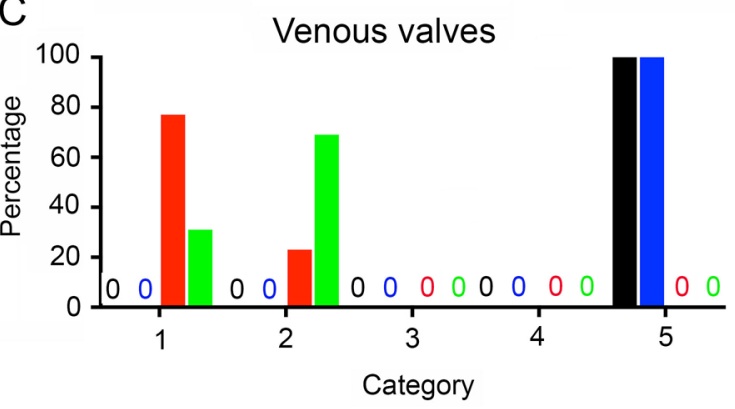

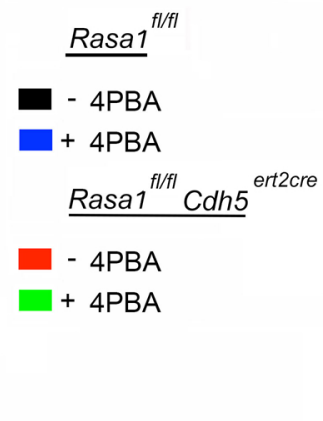

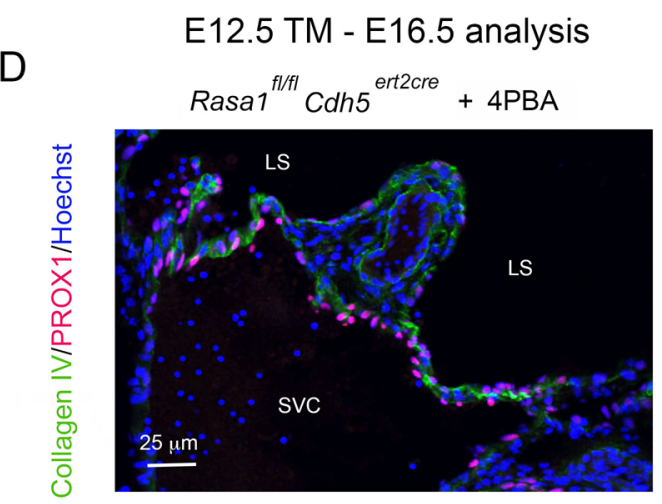

Figure 6. Rescue of LVV Development in induced EC-specific RASA1-deficient embryos by the chemical chaperone 4PBA. A-D, Rasal ${ }^{f l f l}$ and Rasal ${ }^{f l f l} \mathrm{Cdh}^{\text {ert2cre }}$ embryos were administered TM and 4PBA at E12.5 and 4PBA every day thereafter until embryo harvest at E16.5. Longitudinal sections of the neck region (dorsal to ventral from top to bottom) were stained with the indicated antibodies. LS, lymphatic sac; IJV, internal jugular vein; EJV, external jugular vein; SCV, subclavian vein; SVC, superior vena cava. In (A) arrows and arrowheads indicate LVV and VV respectively. $\mathbf{B}$ and $\mathbf{C}$, Percentage of LV-BV junctions from Rasal ${ }^{f l l f l}$ and Rasal ${ }^{f l l f l} C d h 5^{\text {ert2cre }}$ embryos from (A) that contain the indicated number of LVV (B) and categories of VV (C, see Figure 2 D). Rasal $1^{\text {fl/fl }}$ $\mathrm{n}=4$, Rasal $^{\text {fl/fl }}$ Cdh $^{\text {ert2cre }} \mathrm{n}=13$. Note that data from Rasal ${ }^{\text {fl/fl }}$ and Rasal ${ }^{\text {fl/fl }}$ Cdh $^{\text {ert2cre }}$ embryos treated with TM alone from Figure $4 \mathrm{C}$ and $\mathrm{E}$ (red and black bars) is also plotted for comparison. D, Normal deposition of collagen IV in LVV of Rasal $1^{\text {flflfl }} \mathrm{Cdh}^{\text {ert2cre }}$ embryos treated with 4PBA. 
A

E12.5 TM - E16.5 analysis

$\begin{array}{rc}\text { Rasa }^{f / f / f l} & \text { Rasa }^{f / f f l} \text { Cdh5 }^{\text {ert2cre }} \\ +2,4 \text { PDCA } & +2,4 \text { PDCA }\end{array}$
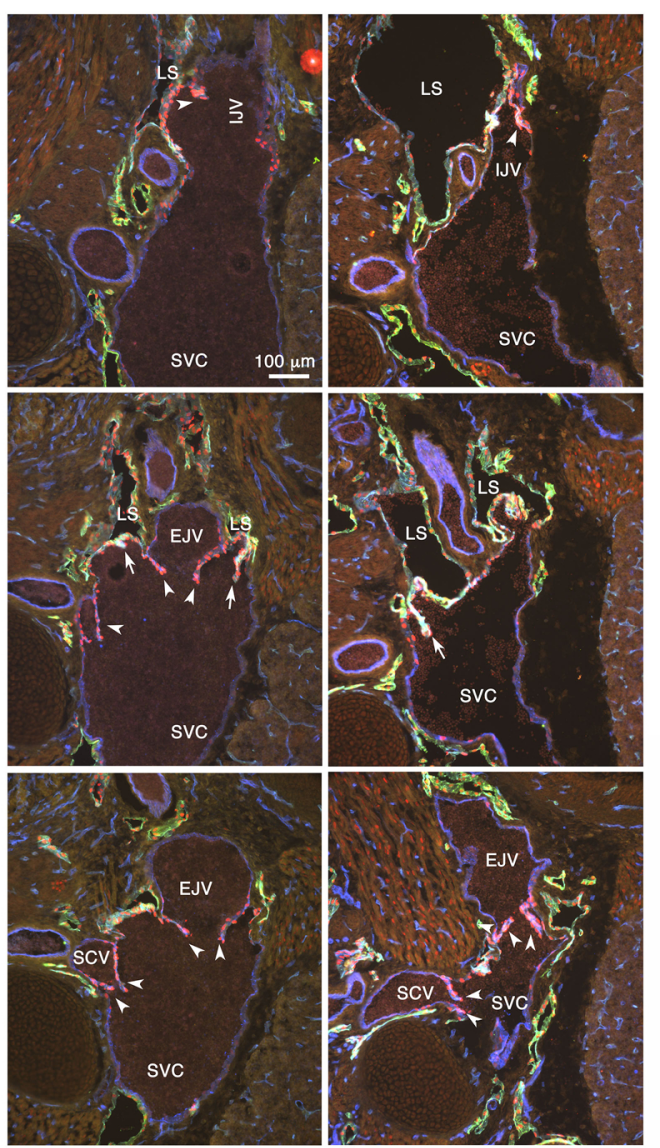

B

Lymphovenous valves

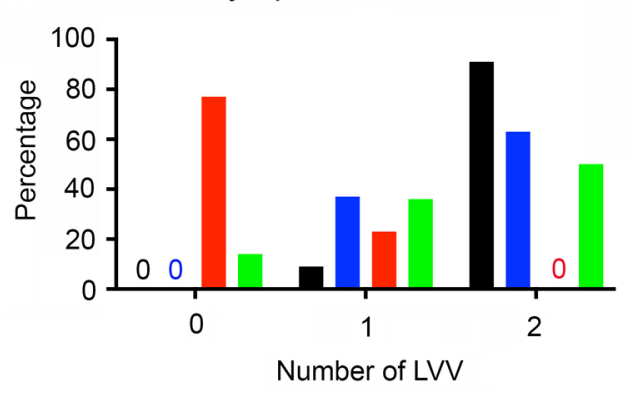

C

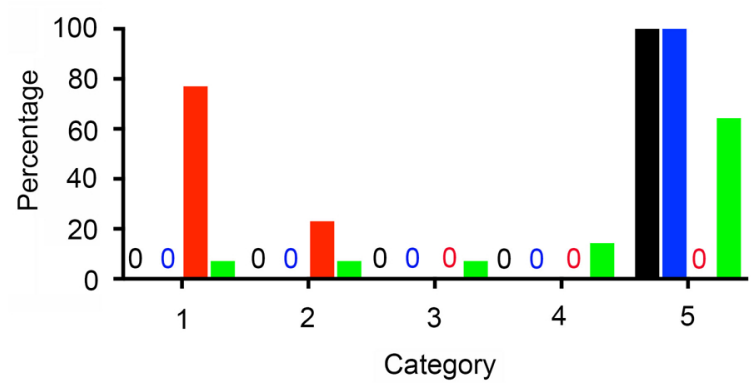

E12.5 TM - E16.5 analysis

$\mathrm{D}$

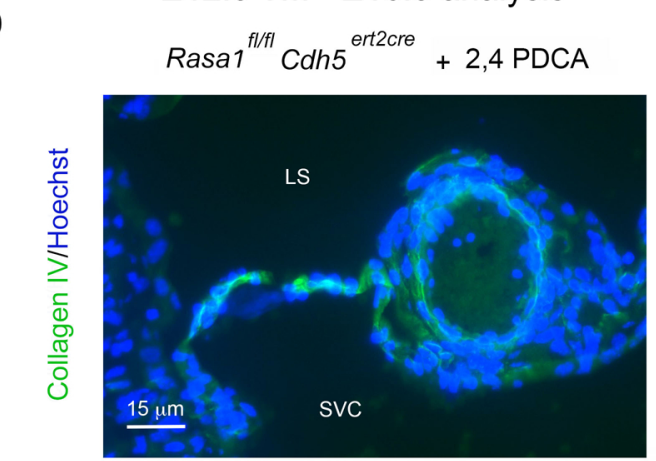

Figure 7. Rescue of LVV development in induced EC-specific RASA1-deficient embryos by 2,4 PDCA. A-D, Rasal $1^{f l f l}$ and Rasal ${ }^{\text {fllfl }}$ Cdh $5^{\text {ert } 2 c r e}$ embryos were administered TM and 2,4 PDCA at E12.5 and 2,4 PDCA every day thereafter until embryo harvest at E16.5. Longitudinal sections of the neck region (dorsal to ventral from top to bottom) were stained with the indicated antibodies. LS, lymphatic sac; IJV, internal jugular vein; EJV, external jugular vein; SCV, subclavian vein; SVC, superior vena cava. In (A) arrows and arrowheads indicate LVV and VV respectively. $\mathbf{B}$ and $\mathbf{C}$, Percentage of LV-BV junctions from Rasal ${ }^{f l f f l}$ and Rasal ${ }^{f l f l} C_{d h} 5^{\text {ert2cre }}$ embryos from (A) that contain the indicated number of LVV (B) and categories of VV (C, see Figure 2 D). Rasa $1^{f l / f l}$ $\mathrm{n}=11$, Rasal ${ }^{f l f l} C_{d h 5^{\text {ert } 2 c r e ~}} \mathrm{n}=14$. Note that data from Rasal ${ }^{f l f l}$ and Rasal ${ }^{f l / f l} C_{d h 5^{\text {ert2cre }}}$ embryos treated with TM alone from Figure $2 \mathrm{C}$ and $\mathrm{E}$ (red and black bars) is also plotted for comparison. D, Normal deposition of collagen IV in LVV of Rasal ${ }^{\text {flflfl }} \mathrm{Cdh}^{\text {ert } 2 \text { cre }}$ embryos treated with 2,4 PDCA. 
A

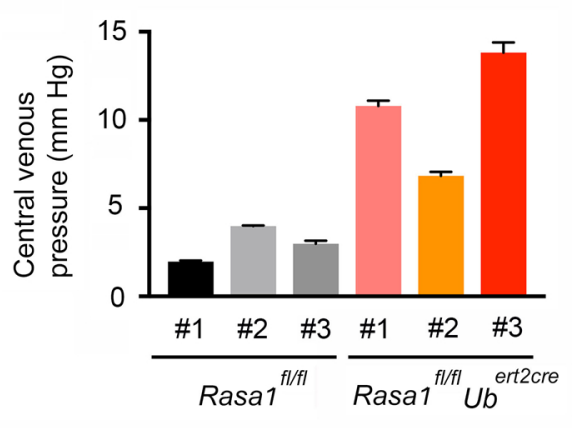

B

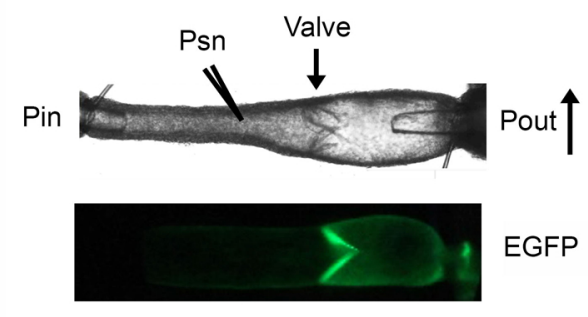

D

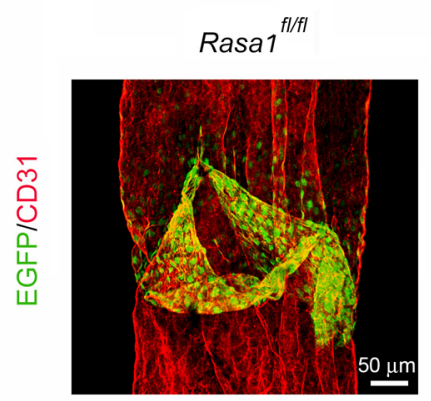

Cervical venous valves

Rasa $1^{\text {fflft }} U b^{\text {ert2cre }}$

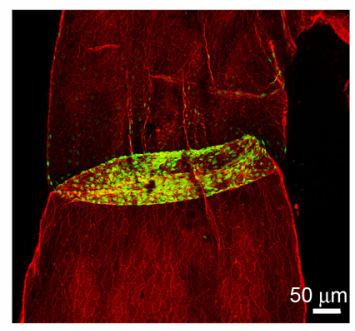

- Rasa1 ${ }^{f / f l}$

- Rasar $1^{f / f}$ Ub ${ }^{\text {ertzcre }}$

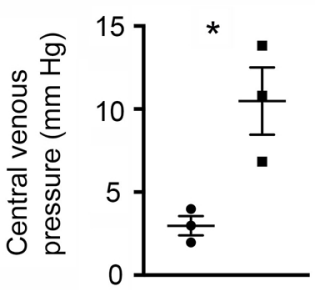

C

Cervical venous valves

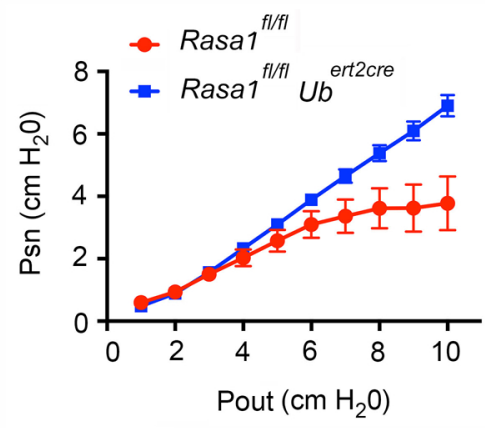

E Cervical venous valves

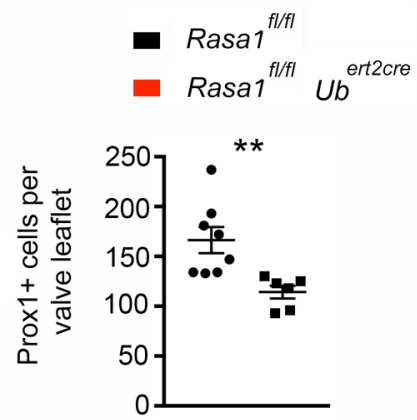

Figure 8. A required role for RASA1 in the maintenance of central VV function in adult mice. A, TM was administered to adult Rasal $I^{f l f l}$ and Rasa $I^{f l / f l} U^{\text {ert } 2 \text { cre }}$ mice and central venous blood pressure was measured by telemetry 3 months later. At left is shown the mean +1 SEM of the central venous pressure for 3 individual mice of each genotype based upon continuous monitoring over 6 days (see Methods). At right is shown the mean +1 SEM of the mean central venous pressure of individual mice at left. *, $P<0.05$; Student's 2-sample t-test. B, Image of a dissected cervical vein from a Prox1-eGFP mouse showing positions of $\mathrm{P}_{\mathrm{in}}, \mathrm{P}_{\text {out }}$ and $\mathrm{P}_{\mathrm{sn}}$ micropipettes in low pressure back-leak assays (top) and the fluorescent eGFP positive VV (bottom). C, Low pressure back-leak tests of cervical VV from adult Rasal ${ }^{f t / f l}$ Proxl-eGFP and Rasal ${ }^{f l f l}$ Ub $^{\text {ert2cre }}$ Proxl-eGFP mice administered TM 3 months previously. Rasal fl/fl Proxl-eGFPn=9, Rasal $1^{\text {flflf }} U b^{\text {ert2cre }}$ Proxl-eGFP $\mathrm{n}=8$. Note leakage of Rasa ${ }^{f l f l} U^{\text {ert } 2 c r e}$ Proxl-eGFP valves throughout the $\mathrm{P}_{\text {out }}$ pressure range. $\mathbf{D}$, Whole mount images of representative cervical veins from Rasal ${ }^{\text {fllfl }}$ Proxl-eGFP and Rasa ${ }^{f l f l} U^{\text {ertzcre }}$ Proxl-eGFP mice in C. Vessels were stained with an anti-CD31 antibody prior to mounting. E, Mean +1 SEM of the number of EC per VV leaflet. Rasal ${ }^{f l / f l}$ Proxl-eGFPn=8, Rasa1 ${ }^{\text {fllfl }} U b^{\text {ert2cre }}$ Proxl-eGFPn=6. **, $P<0.01$, Student's 2-sample t-test. 